\title{
LA LEY APLICABLE A LOS CONTRATOS INTERNACIONALES EN AUSENCIA DE ELECCIÓN POR LAS PARTES
}

\section{THE APPLICABLE LAW TO THE INTERNATIONAL CONTRACTS IN THE ABSENCE OF CHOICE}

\author{
Francisco José Grob Duhalde
}

\begin{abstract}
RESUMEN: El presente estudio tiene por objeto determinar la ley aplicable a los contratos internacionales en defecto de elección por las partes. El estudio se centra principalmente en el análisis del artículo 16 del Código Civil, de manera de precisar su correcto sentido y alcance, a la vez que formula diversas críticas a las posiciones que tradicionalmente la doctrina y jurisprudencia nacionales han adoptado a su respecto. Luego de determinada la ley aplicable tanto a las cuestiones de forma como de fondo, el estudio se aboca a precisar la manera como deben concretarse las conexiones empleadas por el artículo 16, para finalmente concluir refiriéndose a las materias que quedan comprendidas dentro del ámbito de regulación de dicha norma.
\end{abstract}

Palabras clave: Ley aplicable, contratos internacionales, derecho internacional privado, artículo 16.

ABSTRACT: This article aims to determine the law applicable to international contracts in the absence of choice by the parties. The article mainly focuses on the analysis of article 16 of the Chilean Civil Code in order to determine its correct meaning and scope, whereas it makes several criticisms of the positions that the doctrine and case law have traditionally adopted in this regard. After ascertaining the law applicable to the issues of both form and substance, the study focuses on determining how the connections set forth in article 16 should be materialized and then it ends by referring to the matters included within the scope of regulation of article 16 .

Key words: Applicable law, international contracts, private international law, article 16.

\section{INTRODUCCIÓN}

Sin perjuicio de los diferentes matices, actualmente la mayoría de la doctrina y jurisprudencia nacionales está de acuerdo en que las partes de un contrato internacional pueden escoger directamente el derecho aplicable a su convención, en virtud del principio de la autonomía de la voluntad en su variante conflictual.

La situación, sin embargo, es muy distinta cuando se trata de determinar la ley aplicable al contrato internacional, en ausencia de elección de ley por las partes. En efecto, si bien la doctrina coincide, en su mayoría, en que la respuesta a esta interrogante debe bus-

\footnotetext{
Profesor de Derecho Internacional Privado de la Pontificia Universidad Católica de Chile. Abogado. Licenciado en Ciencias Jurídicas y Sociales de la Universidad de Chile. Correo: franciscogrob@gmail.com.
} 
carse en el artículo 16 del Código Civil, persisten las dudas acerca de su correcto sentido y alcance. Lamentablemente los comentarios de los que ha sido objeto esta norma no han contribuido a mejorar esta realidad. Como veremos, al interpretar el artículo 16 la doctrina ha omitido, en general, cualquier referencia a las fuentes históricas que inspiraron el establecimiento de esta disposición, y que ciertamente echan luces respecto a su verdadero sentido, y no ha reparado tampoco en las odiosas consecuencias prácticas que produce la interpretación que mayores partidarios se anota.

En vista de lo anterior, nos proponemos en este trabajo analizar en detalle el problema de la ley aplicable al contrato internacional en defecto de elección por las partes. Para ello, introduciremos este estudio con una breve reseña histórica acerca de la evolución del DIPr en esta materia. En seguida, nos concentraremos en determinar el correcto sentido y alcance que debe atribuirse al artículo 16, tanto en lo que respecta a la regulación de los aspectos de fondo como de forma del contrato internacional, para luego abocarnos a determinar la manera como deben concretarse las conexiones empleadas por ella. Finalmente concluiremos nuestro trabajo proponiendo una reformulación práctica de la regla de conflicto que contiene dicha norma.

Antes de continuar, dejamos constancia de que el análisis que aquí efectuamos se refiere fundamentalmente a contratos patrimoniales y, por lo mismo, debe entenderse sin perjuicio de aquellas materias en las cuales existe una regulación especial, tal como ocurre, por lo general, en el derecho de familia o en el derecho de los consumidores.

\section{BREVE SÍNTESIS HISTÓRICA ACERCA DE LA LEY APLICABLE A LOS CONTRATOS INTERNACIONALES EN LA DOCTRINA COMPARADA}

Al revisar la evolución histórica del DIPr en lo que respecta a la ley aplicable a los contratos internacionales, es posible identificar una serie de tendencias que han tenido notable influencia en el desarrollo de esta disciplina a lo largo de los años ${ }^{1}$. A estas tendencias nos referiremos brevemente a continuación a fin de introducir el presente estudio.

\subsection{Primacía de la "Lex Loci Celebrationis"}

La primera de estas tendencias es, sin duda, la defensa irrestricta de la ley del lugar de celebración o "Lex Loci Celebrationis" (en adelante, también "LLC”) como criterio para determinar la ley aplicable a los contratos internacionales. Dentro de los exponentes de esta doctrina están los primeros estatutarios de la baja edad media ${ }^{2}$. La misma solución además acogieron los canonistas de las universidades medievales. Tanto estatutarios como canonistas, fundaron su posición en la soberanía territorial de cada Estado, la cual, a su juicio, determinaba que los actos celebrados en un territorio quedaran sujetos in toto a la ley de dicho lugar. De lo contrario -argumentaban- se vulneraría la soberanía del Estado en el

\footnotetext{
1 Preferimos no hablar de periodos, pues cada una de estas tendencias ha sobrevivido a sus respectivos periodos de esplendor.

2 Carrascosa (2000) pp. 9-10.
} 
cual el contrato se celebra, y cuyas leyes por tanto deben ser observadas. Esta solución fue recogida luego en las siete Partidas de don Alfonso Décimo el Sabio.

No cabe duda que esta idea resultaba bastante funcional a una época en la cual los contratos internacionales se celebraban normalmente en ferias, mercados y puertos. Sin embargo, a medida que esta realidad fue cambiando, los estudiosos comenzaron a notar las serias deficiencias que esta regla presentaba. Por de pronto, advirtieron que el lugar de celebración bien podía ser meramente fortuito, lo que hacía cuestionar la conveniencia de soluciones centradas en la aplicación de la LLC. Asimismo, y a medida que los medios de comunicación avanzaban, permitiendo con ellos los contratos entre ausentes, las complicaciones de aplicar esta regla a contratos que, en estricto rigor, carecen de lugar de celebración, se tornaban cada vez más evidentes.

Pese a lo anterior, la LLC tuvo una clara y extendida preeminencia entre los estudiosos del DIPr hasta por lo menos el siglo XIX en gran parte del orbe, e incluso comienzos del siglo XX en varios Estados norteamericanos influenciados por el First Restatement of Conflict of Laws (1942).

\subsection{Surgimiento y auge de la "Lex Loci Solutionis" o " Lex Loci executionis"}

Uno de los primeros en cuestionar la aplicación exclusiva de la Lex Loci Celebrationis al contrato internacional fue Bartolo de Sassoferrato (1313-1357), célebre tratadista italiano, a quien se le atribuye la teoría de los estatutos.

Basándose en la Ley Si Fundus del Digesto³, Bartolo sostuvo en sus "Commentarius in Codice al Legem Cunctos Populos", que la forma de los contratos ("solemnitas contractus") y sus consecuencias normales debían regirse por la ley del lugar de su celebración, mientras que sus efectos o consecuencias "irregulares" quedaban sujetos, en caso de acuerdo, a la ley del lugar de cumplimiento y, de lo contrario, a la lex fori. Por efectos o consecuencias "normales" del contrato, Bartolo entendía todo aquello que emana naturalmente de este y se vinculaba con su sustancia, incluido lo relativo a su formación ${ }^{4}$. Por efectos o consecuencias accidentales", en cambio, Bartolo comprendía todo aquello que no es inherente al contrato, sino que se deriva de circunstancias posteriores, como por ejemplo el incumplimiento o la mora del deudor. Estos eventos normalmente se verifican en el lugar de cumplimiento y por ello, según Bartolo, deben quedar regidas por el derecho de dicho lugar 5 . Con esta posición, dicho sea de paso, el autor se erige como uno de los primeros en admitir el fraccionamiento o depecage del contrato en una época en la cual la visión predominante era el sometimiento del contrato internacional in toto a la LLC 6 .

La distinción de Bartolo fue, en general, mantenida por posteriores autores como Nicolaus Burgundus (1586-1649), Ulrich Huber (1636-1694) y Louis Boullenois (1680-1762)7.

\footnotetext{
3 Para una revisión detallada de esta Ley se puede ver: STORY (1834) pp. 194 y ss. (sección 233 y ss.)

4 Dunker (1967) p. 58.

5 Carrascosa (2003) para. 10. En el mismo sentido: Rabel (1958) p. 446.

6 Carrascosa (1992) pp. 52-53.

7 Story (1834) p. 200 (sección 240). En el mismo sentido: Carrascosa (2003), para. 11-12. Véase también: BOULLENOIS (1766), pp. 451 y ss.
} 
Con todo, esta tendencia en pos de la Lex Loci Solutions (en adelante, también "LLS") encuentra sin duda su apogeo en dos de los más grandes autores del DIPr moderno: el connotado juez de la Suprema Corte norteamericana, Joseph Story (1779-1845) y el gran maestro Friedrich Carl von Savigny (1779-1861).

Así, Story sostiene en su obra que, por regla general, los contratos se rigen por la LLC $^{8}$. Cita para ello a una serie de autores que avalarían esta postura. Sin embargo, luego aclara que esta regla presupone que el contrato haya de cumplirse en el lugar en el que se celebró ${ }^{9}$. De lo contrario, continúa Story, el contrato quedará sometido en cuanto a su validez, naturaleza, obligaciones e interpretación a la LLS, y no a la ley del lugar de celebración ${ }^{10}$. En este mismo sentido, por cierto, se había pronunciado antes otro ilustre autor norteamericano, el canciller James Kent (1763-1847) ${ }^{11}$.

Savigny, por su parte, va aún más lejos. Para él, la sede natural de toda obligación es su lugar de cumplimiento ${ }^{12}$. Este lugar, agrega el autor, a diferencia del lugar de celebración, difícilmente podría ser fortuito, por lo que deviene en un punto de conexión ideal para proporcionar una regulación al contrato internacional. Además, este lugar es normalmente determinado por las partes, ya sea expresa o implícitamente, de modo que refleja, en gran medida, su propia voluntad. En suma, Savigny concluye que la LLS debe regir el contrato en su totalidad, sin importar donde haya de solicitarse su cumplimiento judicial y con la sola excepción de las cuestiones de forma del contrato que, según señala, pueden facultativamente quedar sometidas a la LLC o a la propia LLS ${ }^{13}$.

Se aprecia así un claro y gradual avance en pos de la aplicación de la Lex Loci Solutions, aunque no siempre con idéntico significado y alcance.

\subsection{La Autonomía de la voluntad, puntos de COnexión flexibles y unidad de Régimen del Contrato Internacional.}

Ya en el siglo XVI encontramos los primeros postulados en defensa de la autonomía de la voluntad como principio rector en materia de contratos internacionales. Así, en la

\footnotetext{
8 En este sentido, Story señala que "Generally speaking, the validity of a contract is to be decided by the law of the place where it is made. If valid there, it is, by the general law of nations, iure gentium, held valid every where, by tacit of implied consent". STORY (1834) p. 201, sección 242.

9 De acuerdo con Story "The rules already considered suppose, that the performance of the contract is to be in the place, where it is made, either expressly or by tacit implication. But where the contract is either expressly or tacitly to be performed in any other place, there the general rule is, in conformity with the presumed intention of the parties, that the contract, as to its validity, nature, obligation, and interpretation, is to be governed by the law of the place of performance".

10 STORY (1834) p. 201, sección 242.

11 Kent (1827) lección 39, p. 459.

12 SAVIGNY (1849) sección 379 en adelante.

13 SAVIGNY (1849) sección 372. Es importante notar, con todo, que las ideas de Story y Savigny fueron fuertemente resistidas por algunos importantes autores de la época, decididos a conservar la influencia de la LLC en desmedro de la Lex Loci Solutions. Es el caso de: Jean Jacques Gaspard Foelix (1847) [Sección 98], Henry Wheaton (1855) p. 142, y posteriormente, Joseph Baile, férreo defensor del territorialismo y partidario de la teoría de los derechos adquiridos (Vested rights). Este último autor optó por limitar el ámbito de aplicación de la Lex Loci Solutions, confinándola únicamente a lo que podríamos denominar "modalidades de ejecución" del contrato, parafraseando a la doctrina comparada.
} 
obra de Charles DuMoulin (1500-1566) es posible advertir los primeros precedentes de lo que hoy en día la doctrina moderna conoce como autonomía conflictual ${ }^{14}$.

A partir de finales del siglo XIX, comienza ya una clara y sistemática tendencia a aceptar la autonomía de las partes para determinar la ley aplicable al contrato internacional.

Paralelamente, además, y en ausencia de elección de ley, se advierte en la doctrina comparada un paulatino abandono de los tradicionales puntos rígidos de conexión, como lo es la ley del lugar de celebración o la ley del lugar de cumplimiento, y una clara tendencia hacia su reemplazo por puntos de conexión flexibles tales como la Proper law of the Contract en Inglaterra, el principio de proximidad en buena parte de Europa continental o los múltiples criterios surgidos en EE.UU. tras la revolución conflictual ${ }^{15}$.

Asimismo, y cualquiera sea el sistema escogido, es posible apreciar una creciente preocupación por mantener la unidad en la regulación del contrato, ante los problemas de indeterminación y confusión que presentaba en la práctica su fraccionamiento legal ${ }^{16}$.

\section{LEY APLICABLE AL CONTRATO INTERNACIONAL EN CASO DE AUSENCIA O INEFICACIA DE LA ELECCIÓN}

Como adelantamos, si las partes han elegido la ley aplicable al contrato, a ella deberá estarse salvo calificadas excepciones. No es nuestra intención referirnos aquí a los límites y demás particularidades de la autonomía conflictual.

Con todo, quisiéramos dejar en claro, dada la pertinencia con el tema que estamos tratando ${ }^{17}$, que a nuestro juicio la elección de las partes puede ser expresa o tácita, mas no presunta, como proponen algunos autores ${ }^{18}$.

En efecto, la voluntad presunta, a diferencia de la tácita, no se infiere a partir de los términos del contrato, sino que se imputa a las partes como resultado de un proceso mediante el cual se trata de determinar cuál habría sido la ley que las propias partes habrían escogido en caso de haberse representado el problema relativo al derecho aplicable a su convención. Así, y a diferencia de la voluntad tácita, la determinación de la voluntad presunta supone más bien un ejercicio de integración del contrato antes que de interpretación. Como tal, y sin perjuicio de que esta doctrina ha sido ampliamente abandonada en el derecho comparado, y fuertemente criticada por la imprevisibilidad de sus resultados, no puede tener cabida en Chile, desde que no existe norma alguna que autorice a integrar el acuerdo

\footnotetext{
14 En este sentido: Dunker (1967) p. 59 y Carrascosa (2003) para. 16 a 19.

15 Carrascosa (2003) para. 23.

16 Alcorta, (1927) p. 243. En el mismo sentido: Rabel (1958) pp. 451-453.

17 La referencia es pertinente, desde el momento en que la voluntad presunta no deja, prácticamente, espacio a reglas subsidiarias para determinar la ley aplicable al contrato, pues casi siempre será posible "atribuir" a las partes alguna elección sobre la base de esta doctrina.

18 En este sentido, Siebel (1934) pp. 41 y ss., y Villaroel y Villaroel (1990) pp. 351 y ss. Sin embargo, estos últimos autores le llaman, a nuestro juicio, erróneamente tácita, en circunstancias que de sus planteamientos se infiere que, en realidad, están hablando de una voluntad presunta, y no tácita.
} 
de voluntades de las partes, de una forma distinta a la que resulta por vía de la aplicación supletoria del artículo 16 del Código Civil ${ }^{19}$.

De otro lado, estimamos también que tratándose de materias disponibles las partes pueden escoger el derecho aplicable al contrato, ya sea al momento de contratar, después de haber contratado o, incluso, en sus presentaciones judiciales, cuando ambas invocan una misma ley aplicable en la etapa de discusión, sin objeción de la contraria. De ahí que, a nuestro juicio, el pacto electio iuiris bien puede manifestarse en cualquiera de estos momentos, sin que pueda estimarse que la localización que hace el artículo 16 sea imperativa para las partes.

Ahora bien, en ausencia de elección de ley por las partes o cuando la elección fuere ineficaz, será necesario determinar si existe o no tratado internacional que rija el contrato. De existir, a él deberá estarse, con primacía de cualquier otra norma de derecho doméstico chileno $^{20}$. Así ocurrirá, por ejemplo, cuando el contrato sea una compraventa internacional de mercaderías de aquellas regulados por la Convención de Viena de 1980 o cuando se trate de un contrato de transporte comprendido dentro del ámbito de regulación de la Convención de Varsovia.

En cambio, si no existe tratado internacional o, si este resulta insuficiente para zanjar una determinada controversia (dado el natural y limitado ámbito de regulación de estos instrumentos) no quedará más que acudir a las normas de conflicto del foro y, en particular, al artículo 16 del Código Civil.

\section{EL ARTÍCULO 16 DEL CÓDIGO CIVIL COMO NORMA DE CONFLICTO BÁSICA EN MATERIA DE CONTRATOS INTERNACIONALES}

De acuerdo con el artículo 16 del Código Civil:

"Los bienes situados en Chile están sujetos a las leyes chilenas, aunque sus dueños sean extranjeros y no residan en Chile.

Esta disposición se entenderá sin perjuicio de las estipulaciones contenidas en los contratos otorgados válidamente en país extraño.

Pero los efectos de los contratos otorgados en pais extraño para cumplirse en Chile, se arreglarán a las leyes chilenas".

Sobre la base de esta disposición, y a efectos de determinar la ley aplicable al contrato internacional, la doctrina nacional ha distinguido tradicionalmente entre aquellos contratos celebrados en el extranjero para cumplirse en Chile y aquellos celebrados en Chile

\footnotetext{
19 Nótese que las normas de derecho internacional privado normalmente operan supliendo la voluntad de las partes y en su diseño es habitual que se trate de replicar la elección que las propias partes habrían efectuado, en caso de haber previsto el problema. No hay nada de malo en esto. Nuestra objeción a la teoría de la voluntad presunta, en consecuencia, no radica en su método, sino en el hecho que en Chile existe ya una norma que determina el derecho aplicable en defecto de elección por las partes, cual es, el artículo 16 del Código Civil. Esta norma obliga al intérprete, sin que este puede desatender su mandato, salvo, por supuesto, que exista una verdadera (y no presunta) voluntad en contrario de las partes, sea esta expresa o tácita.

20 Véase el artículo 27 de la Convención de Viena de 1969.
} 
para cumplirse en el extranjero. Asimismo, algunos agregan como categoría adicional los contratos celebrados en el extranjero para cumplirse en el extranjero.

En cada uno de estos casos, además, se suele distinguir entre lo que concierne al fondo del contrato y aquello que interesa a su forma. Por razones de orden y claridad, seguiremos un esquema similar.

\section{LEY APLICABLE AL FONDO DEL CONTRATO CELEBRADO EN EL EXTRANJERO PARA CUMPLIRSE EN CHILE}

\subsection{Visión TRADICIONAL}

En vista de lo dispuesto en los incisos segundo y tercero del artículo 16 recién citado, la mayoría de la doctrina nacional -y de manera análoga también la doctrina extranjera de países que adoptaron el Código de Bello ${ }^{21}$ - han sostenido que los requisitos del contrato, tanto internos como externos, se regulan por la ley del lugar de su celebración, mientras que los efectos, entendidos estos como los derechos y obligaciones que emanan del acto, se rigen por la ley chilena cuando el contrato ha de cumplirse en Chile.

Según entendemos, el primero en sostener esta interpretación del artículo 16 del Código Civil fue don Clemente Fabres a finales del XX. En efecto, en su obra titulada "La legislación de Chilena con relación al Derecho Internacional Privado", publicada por primera vez en 1892, el referido autor analiza extensamente las normas de conflicto del Código Civil. Concluye, refiriéndose de la ley aplicable a los contratos, que "Los requisitos necesarios para el valor del contrato, ya sean internos, ya sean externos, se rigen por la ley del país en que se celebra (...)" 22 y que "los efectos, o sea, los derechos y obligaciones, se rigen por la misma ley, salvo que el contrato se haya celebrado para cumplirse en Chile, pues entonces se arreglarán a la ley chilena" 23 .

Esto último significa según Fabres que, por una parte, "las estipulaciones consignadas en él deben ajustarse a la ley chilena lo mismo que si se hubieran celebrado en Chile" 24 $y$, por la otra, que "los derechos y obligaciones que son de la naturaleza del contrato y que se producen sin necesidad de estipulación expresa, son exactamente iguales en los contratos que se celebran en Chile que en los que se celebran en el extranjero para cumplirse en Chile" 25 . En otras palabras, "es lícito hacer en los contratos referidos las mismas estipulaciones que podrían hacerse en los contratos que se celebren en Chile, y que a falta de estipulaciones especiales, los dichos contratos producen los derechos y obligaciones que determinan las leyes chilenas"26.

\footnotetext{
21 Aljure,(2007) p. 351 y ss.

22 FABRES (1908) p. 170

23 Fabres (1908) p. 190. En el mismo sentido, Domínguez (1966) p. 298 y GuZmán (1989) p. 524.

24 Fabres (1908), p. 166. En el mismo sentido, Domínguez (1966), p. 298. Diego Guzmán, por su parte, en línea con este planteamiento sostiene que a consecuencia de la sujeción de los efectos a la ley chilena "no se podrán hacer estipulaciones en ese contrato [celebrado en el extranjero] que violasen la ley chilena, no podrían hacerse otras estipulaciones que las que podrían hacerse en Chile”. GuZMán (1989) p. 524.

25 FABRES (1908) p. 176-177.

26 FABRES (1908) p. 176.
} 
Es decir, siguiendo la teoría de los actos jurídicos, Fabres sostiene que los "efectos" a los cuales alude el inciso tercero del artículo 16 no son otros que los derechos y obligaciones que emanan del acto. En consecuencia, si bien defiende la aplicación de la LLC a los requisitos de validez del contrato, excluye de su ámbito de aplicación todo aquello que concierne a los derechos y obligaciones del contrato cuando este haya de cumplirse en Chile. En este mismo sentido, se pronuncian Claro Solar ${ }^{27}$, Alessandri y Somarriva ${ }^{28}$, Ducci ${ }^{29}$, Domínguez ${ }^{30}$, Guzmán ${ }^{31}$ y Ramírez ${ }^{32}$, todos ellos siguiendo a Fabres. También la jurisprudencia ha acogido esta interpretación en algunos fallos, aunque usualmente en obiter dicta ${ }^{33}$.

En consecuencia, nuestro Código admitiría lo que la doctrina comparada ha denominado -aunque no sin antes resaltar su inconveniencia- un fraccionamiento o depecage del fondo del contrato internacional, sometiendo diversas "partes" del mismo a leyes distintas ${ }^{34}$.

Como dejamos entrever en la introducción de este trabajo, nosotros no estamos de acuerdo con esta doctrina. Y no lo estamos, porque, a nuestro juicio, ella se funda en una errada interpretación del artículo 16 que no se condice con las fuentes que inspiraron el establecimiento de esta norma y que presenta, además, serias contradicciones lógicas que la tornan, sino impracticable, a lo menos altamente inconveniente. A continuación desarrollaremos estos planteamientos.

\subsection{CorReCto SENTido y ALCANCE DEL ARTí́culo 16}

Como decíamos, la doctrina ha reconocido tradicionalmente en el inciso segundo del artículo 16 una suerte de consagración al principio LLC, fundado principalmente en su propio tenor literal ${ }^{35}$. Nosotros coincidimos con esta postura en la medida en que el contrato haya de cumplirse en el mismo país en el cual se otorgó. De lo contrario, regirá lo dispuesto en el inciso siguiente.

Aquí, sin embargo, es donde surge el gran problema. La doctrina ha interpretado generalmente dicho inciso y, en particular, la voz "efectos" allí empleada, como sinónimo de los derechos y obligaciones que emanan del contrato, distinguiéndolos claramente de los requi-

\footnotetext{
27 Claro Solar (1978) pp. 113 y ss.

28 Alessandri y Somarriva (1998).

29 DuCCI (2000) p. 80 y ss.

30 Domínguez (1966) pp. 295 y ss.

31 GuZMán (1989) pp. 523 y ss.

32 Ramírez (2007) pp. 75-76.

33 Así, se ha fallado que fallado que "Los requisitos internos, o sea, las condiciones indispensables para la validez de un acto jurídico $-\mathrm{y}$ que miran a la capacidad de las personas, el consentimiento de las partes y al objeto de la disposición-, y los requisitos externos o formalidades -que dicen relación al modo de declarar o comprobar el consentimiento- se rigen por la ley del lugar en que el acto o contrato se celebró con las solas excepciones indicadas en el inciso $1^{\circ}$ del art. 5 y del art. 18 del Código Civil”. Véase: Ferrer con Banco Español de Chile e Liquidación (1931).

34 RABEL (1958) pp. 450-453.

35 En contra: Albónico (1950) p. 88. Para este autor la referida disposición señala que "los bienes puedan quedar regidos por una ley extranjera en virtud de estipulaciones contenidas en los contratos otorgados válidamente en país extraño (...) pero no indica en parte alguna que el valor de dichos contratos y menos sus formas, queden sujetos a las leyes del lugar”.
} 
sitos internos de todo acto. A partir de esta construcción se afirma que si el contrato ha de cumplirse en un país distinto de aquel en el cual se otorgó, solo los derechos y obligaciones, mas no sus requisitos, quedarán entregados a la LLS. Así lo sostuvo Fabres poco después de promulgado el Código, invocando al efecto categorías propias de la teoría de los actos jurídicos, y luego de él todos los autores que le siguieron, prácticamente sin excepción.

Como demostraremos, sin embargo, cuando el inciso tercero del artículo 16 señala que los "efectos" de los contratos otorgados en el extranjero para cumplirse en Chile se arreglarán a la ley chilena, no está haciendo referencia a los derechos y obligaciones del contrato, sino que, de manera mucho más general, a todas las consecuencias jurídicas del contrato incluidas las condiciones para que haya lugar a estas, salvo únicamente lo relativo al cumplimiento de la forma o solemnidades que eventualmente pudieran exigirse.

En consecuencia, expresada la voluntad en la "forma" establecida por la LLC (si es que hubiera alguna) y, desde esa perspectiva, otorgado el contrato válidamente en país extraño en los términos del inciso segundo del artículo 16, si el contrato ha de cumplirse en Chile, quedará regulado en todo lo demás por el derecho chileno. Luego, el que las consecuencias jurídicas (los "efectos") queden entregadas a la ley chilena, importa que sea ella y no otra, quien determine cuáles son los requisitos o condiciones sustantivas que el acto deberá cumplir para que haya lugar a estas ${ }^{36}$.

De ahí que el contrato quedará sometido en todo lo que normalmente se asocia al fondo del mismo a la LLS; es decir, tanto en lo relativo a sus requisitos de validez como a los derechos y obligaciones que de él emanan, sin que sea procedente fraccionarlo, distinguiendo entre unos y otros.

\subsubsection{Historia fidedigna del establecimiento del artículo 16}

Como adelantamos, a esta interpretación nos conduce la historia fidedigna del establecimiento de esta norma.

En efecto, el artículo 16 del Código Civil, en la parte que nos interesa, encuentra su antecedente inmediato en el artículo 14 del Proyecto de Código de 1853. Esta norma establecía originalmente que "Los efectos legales de los contratos otorgados en territorio extranjero para ejecutarse en Chile, se arreglarán a las leyes chilenas".

Como se puede apreciar, esta norma habla de "efectos legales", en lugar de efectos a secas o efectos jurídicos, lo que ya da cuenta, a nuestro juicio, del especial alcance de esta expresión, el que no debe entenderse constreñido a los meros derechos y obligaciones que el acto genera. Pero hay más.

Según las propias notas de Bello, el inciso tercero del artículo 16 proviene del artículo 10 del Código Civil de Luisiana de 1825. De acuerdo con este artículo: "The form and effect of public and private instruments are governed by the laws and usages of the places where they are passed.

But the effects of acts passed in one country to have effect in another country, are regulated by the laws of the country where such acts are to have effect (...)"

\footnotetext{
36 Nótese además que si quien celebra o ejecuta el acto es chileno será también la ley chilena la que determine su capacidad, en virtud de lo dispuesto en el artículo 15 número 1 del Código Civil.
} 
Como se puede ver, esta disposición solo distingue y contrasta "forma" y "efectos". De ahí que lo que no queda comprendido en una de estas categorías, queda necesariamente comprendido en la otra. Luego, de conformidad con esta disposición, la forma y efecto de los instrumentos se rige por el lugar de su otorgamiento. Sin embargo, si el acto que consta en el instrumento se va a ejecutar en un país distinto de aquel en que se otorgó, sus efectos, según dispone el inciso segundo, se regirán por la LLS y no por la LLC.

A nuestro juicio, Bello siguió en esta materia la misma distinción entre forma y efectos. De hecho, salvo por el carácter unilateral del actual inciso tercero del artículo 16, propio de la filosofía conflictual del redactor de nuestro Código, dicho inciso es prácticamente idéntico al inciso segundo del artículo 10 del Código de Luisiana, a la vez que el artículo 17 de nuestro Código, al cual nos referiremos más adelante, sigue muy de cerca al inciso primero de la misma norma.

Nótese que parte importante de la jurisprudencia y doctrina norteamericanas han interpretado el artículo 10 del Código de Luisiana, precisamente, con el alcance que postulamos; es decir, como un reconocimiento a la aplicación de la LLS en todo lo relativo a la regulación del contrato internacional (y no solo a sus derechos y obligaciones), cuando este haya de cumplirse en un país distinto de aquel en que se otorgó ${ }^{37}$.

De hecho, aunque no está del todo claro cuál fue la fuente de inspiración de esta disposición del Código de Luisiana, replicada en nuestro Código, hay quienes sostienen que responde a los postulados de Story ${ }^{38}$. Para él, como sabemos, la regla general era que los contratos se sujetaran a la LLC, salvo, precisamente, que el contrato fuera a cumplirse en un país distinto de aquel en que se otorgó; en cuyo caso "the contract, as to its validity, nature, obligation, and interpretation, is to be governed by the law of the place of performance" 39 .

Esta original manera de Story de formular la norma de conflicto mediante una regla general, seguida de una excepción, explicaría también la particular redacción del referido artículo 10 del Código de Luisiana (y del inciso tercero del artículo 16 de nuestro Código Civil) en clave de excepción ${ }^{40}$.

Asimismo, y sin perjuicio de que una vez promulgadas las leyes ellas se independizan de su redactor, la interpretación que postulamos es, en nuestra opinión, la única consistente con los planteamientos de Bello, según dan cuenta sus propios escritos. En efecto, y en línea con lo que sería luego el artículo 16 de nuestro Código Civil, Bello sostenía ya en la edición de su obra de derecho internacional de $1844^{41}$ que "Todo contrato, por lo que toca a su valor, su inteligencia, las obligaciones que impone y el modo de llevarlas a efecto, debe arreglarse a las leyes del país en que se ajusta [celebra]; pero si ha de ejecutarse en otro país, se le

\footnotetext{
37 McComic (1964) p. 729. Véase, en particular, la nota al pie No 23.

38 МсСоміс (1964) p. 731.

39 STORY (1834) p. 233, sección 280.

40 Así, quienes defienden esta tesis, sostienen que si bien la primera edición del tratado de Story ("Commentaries on the Conflict of Laws") salió publicada recién en 1834, sus fallos fueron conocidos desde mucho antes en Luisiana, y ellos ya daban cuenta de su doctrina.

41 Hemos tomado en cuenta esta edición de sus "Principios del Derecho de Gentes" (posteriormente retitulado como "Principios de Derecho Internacional”) por ser la más próxima a la redacción del Código.
} 
aplican las leyes de este último" ${ }^{42}$. Bello cita al pie de página de esta afirmación la obra del tratadista norteamericano Jonathan Elliot, específicamente en su párrafo $248^{43}$. Pues bien, tal y como da cuenta dicha obra, el pasaje al cual hace alusión Bello no es sino un extracto del fallo "Van Riemsdyk v. Kane", pronunciado en 1812 ni más ni menos que por Joseph Story $^{44}$. Dicho fallo recoge con meridiana claridad la doctrina de Story a favor de la LLS con el alcance que hemos postulado, cada vez que el contrato haya de cumplirse en un país distinto de aquel en que se celebró.

Esta, además, es la misma doctrina de James Kent a quien Bello cita en varias ocasiones en su obra al referirse, precisamente, a la ley aplicable a las obligaciones contractua$\operatorname{les}^{45}$. Para qué decir de Savigny, férreo defensor del lugar de cumplimiento como punto de conexión verdaderamente gravitante en materia de contratos internacionales, a cuyas obras también sabemos que Bello tuvo acceso mientras elaboraba el Código Civil ${ }^{46}$.

En consecuencia, y a la luz de estos antecedentes, estimamos que las referencias de Bello a la LLC deben entenderse limitadas exclusivamente a aquellos casos en los cuales el contrato ha de ejecutarse en el mismo país donde se celebra. De lo contrario, el contrato se rige por la $L L S^{47}$. Así, por lo demás, lo había entendido alguna jurisprudencia antes de la obra de Fabres ${ }^{48}$.

42 Bello (1844) p. 73.

43 Elliot (1834) p. 296.

44 En efecto, en el fallo "Van Reimsdyk v. Kane" de 1812 Story expresa lo siguiente: "The rule is well settled, that the law of the place, where a contract is made, is to govern, as to the nature, validity, and construction of such contract; and that being valid in such state, it is to be considered as equally valid, and to be enforced everywhere (...) It would seem to follow from this doctrine, that if a contract be void by the law of the place where it is made, it is void everywhere (...), and that what is a discharge of a contract in the place where it is made, shall be of equal avail in every other place (...). To the last position there is an exception, when the contract is to be executed in a place different from that where it is made; for the law of the place of the execution will in such cases apply".

45 Así, KENT señala que la regla general es la LLC. Sin embargo, luego agrega que "But if a contract be made under one government, and is to be performed under another, and the parties had in view the laws of such other country in reference to the execution of the contract, the general rule is, that the contract, in respect to its construction and force, is to be governed by the law of the country or state in which it is to be executed". KENT (1827) lección 39, p. 459. Por cierto, Story también cita a Kent en apoyo de su regla.

46 Con todo, ha de reconocerse que Bello no lo cita en sus notas al margen del artículo 16, sino que al margen del artículo 955 del Código.

47 Tampoco obsta a esta conclusión, la llamada teoría de la incorporación de Bello, como parecieran insinuar Villaroel y Villaroel (1990) p. 363. En efecto, tal y como lo había entendido correctamente alguna jurisprudencia hasta antes de la obra de Fabres, aquellas leyes que se entienden incorporadas al contrato cuando este ha de ejecutarse en el extranjero son estas últimas, y no las del lugar de celebración. En este sentido: [G.T. 1882 , No 129 , p. 81 ]. No por nada Bello se refiere a la incorporación de las leyes que "afectan" al contrato justo después de formular la regla LLS para los contratos que hayan de cumplirse en un lugar distinto de aquel donde se celebran. Además, y tal como consta de la nota al pie, la referencia de Bello a la "teoría de la incorporación" también proviene de la obra de Kent, por lo que no corresponde interpretarla de manera inconsistente con sus postulados. Véase: ElLiot (1834) p. 296 y p. 302; y Bello (1844) p. 73.

48 Con buen criterio práctico, aunque sin mayor desarrollo se puede ver: Corte de Apelaciones de Concepción (1882) p. 81 y ss. 


\subsubsection{Vicios lógicos de la doctrina tradicional}

Como decíamos más atrás, la interpretación de Fabres y sus seguidores no solo se opone a las fuentes que inspiraron el establecimiento del artículo 16, sino que además presenta contradicciones lógicas que sino la tornan derechamente impracticable, a lo menos la hacen altamente inconveniente.

En efecto, los mismos autores que señalan que, de conformidad con el inciso tercero del artículo 16, solo los derechos y obligaciones del contrato quedan regidos por la ley chilena cuando este haya de cumplirse en nuestro país, no dudan en sostener, acto seguido y sin matiz alguno, que los requisitos de validez del contrato se encuentran, en todo caso, sujetos a la LLC.

Como se puede apreciar, esta posición asume que ambas "partes" del contrato son extremos perfectamente diferenciables e independientes, de suerte que basta con identificar cada uno de ellos para delimitar con total claridad hasta dónde llega la esfera de acción de la LLC (requisitos de validez) y dónde parte la de la LLS (derechos y obligaciones). De hecho, Fabres, que como decíamos es el padre de esta interpretación, fue particularmente enfático a este respecto en su obra.

Sin embargo, si bien esta distinción puede ser admitida a los efectos de determinar la ley aplicable a ciertos tipos muy específicos de contratos (como es el caso del matrimonio), en general no tiene cabida en el derecho internacional privado cuando se trata de determinar la ley aplicable a los contratos internacionales ${ }^{49}$. No por nada los dos o tres países en donde se aplicó alguna vez una regla similar a la interpretación que postula Fabres en relación con nuestro artículo 16 , la abandonaron rápidamente ${ }^{50}$.

En efecto, trasladadas a esta disciplina ambas categorías se superponen al punto que resulta verdaderamente imposible trazar una línea divisoria entre una y otra para delimitar la aplicación de la LLC y la LLS. Así, de hecho, lo había denunciado ya hace varias décadas el maestro Ernst Rabel, destacando los inconvenientes de fraccionar el fondo del contrato para determinar la ley aplicable al mismo ${ }^{51}$.

Basta con observar lo que ocurre cuando se trata de precisar la legalidad del contrato para constatar lo que estamos diciendo.

Como tal, la licitud del objeto de un contrato está comprendida dentro de los requisitos de validez del mismo y, por tanto, debería sujetarse a la LLC, según los planteamientos de Fabres. Sin embargo, en la concepción tradicional, el objeto del acto corresponde también a los derechos y obligaciones que de él emanan, los cuales están, en cambio, sujetos a la LLS, según el mismo Fabres. ¿¿Cuál es entonces la ley encargada de precisar la lici-

\footnotetext{
49 Así, enseña Goldschmidt que "Los efectos de un contrato suponen, como cuestión previa, su validez. En el matrimonio, contrato muy especial, se aplica en este orden de ideas rigurosamente el método analítico: la validez del matrimonio se rige por una ley; sus efectos, en cambio, por otras leyes, ya que inclusive se someten los efectos personales a otro Derecho que los patrimoniales. Pero con miras a los contratos comunes la misma ley que regula la validez, también indica sus efectos" GoldsChmidT (1990) p. 101.

50 Véase: RabeL (1958) pp. 451-453. El autor cita unos cuantos fallos del Tribunal Federal Suizo, la Corte Suprema norteamericana y el Reichsgericht alemán, haciendo énfasis en que todos estos precedentes fueron rápidamente superados.

51 RABel (1958) pp. 452-453.
} 
tud o ilicitud del contrato? ¿La LLC aplicable a los requisitos de validez o la LLS aplicable a los derechos y obligaciones?

Este problema es evidente para todos aquellos que consideran que el objeto del contrato coincide con los derechos y obligaciones que este produce. Pero también lo es para aquellos que fundados en los artículos 1.460 y 1.461 del Código Civil identifican el objeto del contrato -más bien- con la prestación sobre la cual recae la obligación contractual (es decir, aquella concreta actividad que se espera del deudor y que puede consistir en dar, hacer o no hacer algo), pues la prestación forma parte de la obligación, de tal modo que no hay forma que pueda considerarse de manera independiente y sujetarse a una ley distinta ${ }^{52}$.

Esta contradicción, por lo demás, salta a la vista en la propia obra de Fabres, cuando el autor señala, por una parte, que "Los requisitos necesarios para el valor del contrato, ya sean internos, ya sean externos, se rigen por la ley del pais en que se celebra (...)"53, sin importar donde haya de cumplirse. Y luego agrega, sin embargo, que si "el contrato se celebra en el extranjero para cumplirse en Chile; entonces los efectos de este contrato, esto es, los derechos y obligaciones que produce, se rigen por la ley chilena" ${ }^{4}$, por lo que "no se podrían hacer estipulaciones en ese contrato que violasen la ley chilena, ni podrian hacerse otras estipulaciones que las que podrian hacerse en Chile" ${ }^{” 5}$. ¿El contrato entonces debe ser lícito según la LLC o según la LLS?

Como se puede apreciar, y aunque en general los partidarios de esta doctrina jamás lo admiten, e insisten en la pretendida delimitación de la esfera de acción de una y otra ley, lo cierto es que esta interpretación del artículo 16 conduce, en definitiva, a aplicar cumulativamente la LLC y la LLS a los requisitos de licitud del objeto, de suerte que el contrato no será válido, a menos que cumpla con las prescripciones que ambas leyes imponen ${ }^{56}$.

Sin embargo, esta lectura del artículo 16 debe ser rechazada por varios motivos.

En primer lugar, porque importa renunciar al propósito localizador de toda norma de conflicto desde la formulación de Savigny, aplicando simultáneamente al contrato inter-

\footnotetext{
52 Particularmente ilustrativas en este sentido resultan las palabras de don Ramón Domínguez cuando, refiriéndose al objeto en nuestro código civil, señala que “(...) al definir el objeto a partir de las obligaciones o de las prestaciones que se generan por el negocio, se coloca al objeto entre los efectos de este, que suponen, desde luego, que el negocio ya se formó". Luego continúa el mismo autor y señala que "de aceptarse esta teoría, debería precisarse que el negocio mismo no tiene objeto, sino efectos (...)”. Domínguez (2013) p. 126. A nuestro juicio, lo único que verdaderamente puede separarse y sujetarse a una ley distinta es el objeto de la prestación en las obligaciones de dar. En tales casos, el objeto de la prestación se confunde con la cosa misma. Pero aquí entramos en el plano de los bienes, cuya regulación el inciso primero del artículo 16 confía a la ley del lugar de su situación, por lo que la LLC no tiene ninguna injerencia.

53 Domínguez (2013) p. 170. En el mismo sentido, agrega Fabres "En cuanto al valor del contrato, o sea, los requisitos, todos los contratos celebrados en el extranjero sin distinción, se rigen por la ley del lugar de la celebración, aunque se hayan otorgado para cumplirse en Chile” FABRES (1908) p. 171.

54 FABRES (1908) p. 190.

55 FABRES (1908) p. 190.

56 De hecho, probablemente conscientes de ello, en el proyecto alternativo presentado por el gobierno de Chile en el Congreso de Montevideo de 1888, basado en una primacía de la LLC, se establecía una norma que disponía de manera expresa la aplicación cumulativa al contrato de "los requisitos especiales para su validez" contemplados también por la LLS. Este proyecto puede consultarse en la obra de Fabres en la cual se acompaña como anexo: FABRES (1908) pp. 312-318.
} 
nacional más de una ley, sin importar cuál es el ordenamiento con el cual está más fuertemente vinculado.

En segundo lugar, porque tal como vimos, semejante interpretación no tiene asidero alguno a la luz de las fuentes del artículo 16, las cuales demuestran que el contrato debe regularse por la ley del lugar de cumplimiento, cuando este difiere del lugar de su celebración; y no por ambas.

Y, por último, porque sujetar cumulativamente un mismo acto a dos leyes distintas impone una excesiva carga a las partes que pondrá además muy probablemente en riesgo la validez de dicho acto, sin que con ello se sirva ningún propósito que lo justifique.

En efecto, y tal como nos enseña una vez más Rabel, difícilmente puede justificarse un interés del Estado del lugar de celebración del contrato en regular los términos de dicho acuerdo, por el simple hecho de que las partes contraten en ese lugar. Más aún cuando el contrato ha de cumplirse en otro Estado ${ }^{57}$. Pero aún si así fuera, y lo que se busca es imponer a las partes cierto respeto y deferencia hacia leyes e intereses sensibles del Estado en donde contratan, resulta bastante más razonable acudir a la noción de orden público (aunque en este caso sea en su variante extranjera), en tanto los intereses afectados así lo ameriten; en lugar de hacer aplicable la totalidad del ordenamiento jurídico de dicho Estado, sin discriminación de ninguna clase ${ }^{58}$. Así, por cierto, lo ha hecho la doctrina y jurisprudencia comparadas en situaciones de algún modo comparables ${ }^{59}$.

En suma, una correcta interpretación del artículo 16 del Código Civil y, en particular, de la voz "efectos" empleada en su inciso tercero, importa a nuestro juicio que cada vez que el contrato se haya celebrado en país extraño para cumplirse en Chile, este deberá sujetarse a la ley chilena en todos sus aspectos, salvo únicamente por lo relativo al cumplimiento de la forma que pudiera ser necesario observar, y sin perjuicio del recurso al orden público, según señalamos.

5.3. Contratos celebrados en Chile para cumplirse en el extranjero y, en GENERAL, CONTRATOS CELEBRADOS EN UN LUGAR PARA CUMPLIRSE EN OTRO

Como decíamos anteriormente, a efectos de determinar la ley aplicable al contrato internacional la doctrina y jurisprudencia han distinguido tradicionalmente entre aquellos contratos celebrados en el extranjero para cumplirse en Chile, analizados en el capítulo precedente, y aquellos contratos celebrados en Chile para cumplirse en el extranjero. Tratándo-

\footnotetext{
57 Rabel (1958) pp. 309-401.

58 Sin ánimos de entrar aquí al análisis pormenorizado de esta institución, a nuestro juicio es, en principio, posible invocar la vulneración al orden público de la ley del lugar de celebración para objetar la validez de un contrato que, por tener que cumplirse en Chile, está sujeto a la ley chilena en lo que respecta a su legalidad, según la interpretación del artículo 16 que defendemos. Ciertamente que esto no es lo mismo que hacer cumulativamente aplicables al contrato los requisitos de la ley chilena, más los de la ley del lugar de celebración, pues la noción de orden público es necesariamente limitada y restringida, de suerte que solo pueden ampararse por ella intereses esenciales o fundamentales, y no cualquier requisito o prohibición que la ley del lugar de celebración pudiera contemplar.

59 Para ambos, véase: Hartley (2009) pp. 599 y ss. y Boggiano (1995).
} 
se de estos últimos es posible advertir básicamente tres posiciones cada una de las cuales se anota algunos fallos en su favor.

Así, para algunos como Alessandri y Maluenda la ley chilena nada puede disponer acerca de un contrato celebrado en Chile si este no va a producir efectos en nuestro país ${ }^{60}$. Sin embargo, nada dicen estos autores respecto a cuál es, entonces, la ley que debe regir estos contratos si es que son sometidos al conocimiento de tribunales chilenos. Al parecer, olvidan que una cosa es la ley aplicable al contrato y otra distinta es el foro competente para conocer de una determinada controversia que puede nacer con ocasión de dicho contrato. Así, bien puede ocurrir que un contrato celebrado en Chile para cumplirse en el extranjero, sea sometido al conocimiento de los tribunales chilenos porque, por ejemplo, el demandado tiene su domicilio en Chile, en cuyo caso es evidente que el tribunal chileno, en virtud del principio de inexcusabilidad, no puede eludir resolver el asunto argumentando que "no tiene por qué inmiscuirse en el caso". Debemos descartar, en consecuencia, esta posición.

Otros autores, en cambio, como Albónico, sostienen que en virtud de lo dispuesto en el artículo 14 del Código Civil, cuando el contrato se celebre en Chile, aunque vaya a cumplirse en el extranjero, "la legislación nacional envuelve al contrato, si pudiéremos decir, y queda totalmente regido por nuestras leyes" ${ }^{31}$. Es decir, bastaría con que el contrato se haya celebrado en Chile para que quedara absolutamente regido por la legislación chilena, tanto en lo concerniente a su formación como a sus efectos, sin importar el lugar donde haya de cumplirse.

A nuestro juicio, sin embargo, si bien el artículo 14 constituye una muestra del espíritu territorialista de nuestro legislador, inferir a partir de ello una conclusión como la de Albónico nos parece del todo desproporcionado e infundado. Basta con recordar al respecto que, tal como lo ha hecho presente la doctrina comparada, el principio de territorialidad no tiene por qué favorecer la aplicación de la LLC; menos aún, cuando el acto produce efectos en otro territorio y bien podría, entonces, justificarse la aplicación de la LLS en su virtud $^{62}$. En consecuencia, tampoco pareciera ser esta la posición correcta.

Por último, están los que, como Ramírez y los hermanos Villaroel, postulan que tratándose de contratos celebrados en Chile para cumplirse en el extranjero lo que corresponde en estos casos es "bilateralizar" la norma de conflicto del artículo 16 del Código Civil y de esta forma aplicar por analogía el mismo principio que subyace al referido artículo $16^{63}$.

\footnotetext{
${ }^{60}$ Así, Maluenda señala que "Los contratos celebrados en Chile para producir efectos en el extranjero no se encuentran previstos en nuestro Derecho en ninguna norma expresa. Estos contratos, quedan incluidos en el concepto de contrato internacional y, por tanto, desde el punto de vista del Derecho chileno, podrá escogerse el Derecho aplicable. Sobre sus efectos, sin embargo, la ley chilena nada podrá preceptuar, pues no tendría autoridad para referirse a ellos, por tener que ejecutarse en el extranjero" MALuENDA (1998) p. 137. Alessandri, por su parte, de manera similar sostiene que "es menester considerar si el acto va a producir o no efectos en Chile. Si no los va a producir, no hay cuestión: la legislación chilena no tiene por qué inmiscuirse en el caso" ALESSANDRI (1998) p. 288. En este mismo sentido, véase: Banco de Tacna con Espada y Donoso Hmnos. (1930).

61 Albónico (1943) p.145. En contra: Maluenda (1998) p. 138.

62 Esta es la lógica que subyace tras el Restatement (First) on Conflicts of Laws de 1934. Véase también: WHEeler COOK (1936) p. 157.

63 Ramírez (2007) p. 76 y Villaroel y Villaroel (1990). Con todo, estos autores no limitan el alcance de la excepción del inciso tercero a los derechos y obligaciones del contrato, postura que, como hemos explicado, no compartimos en absoluto.
} 
Nosotros nos inclinamos sin duda por esta última postura. A nuestro juicio, el legislador ha mostrado una clara voluntad a fin de dar primacía al lugar de cumplimiento como criterio de conexión verdaderamente gravitante cuando el contrato ha de cumplirse en un lugar distinto de aquel en que se celebró. Si no formuló la norma en términos bilaterales fue simplemente por la filosofía conflictual que inspiraba al redactor del Código.

En consecuencia, no habiendo norma que se pronuncie en sentido diverso, lo que corresponde de conformidad con el espíritu que informa a nuestra legislación, es "bilateralizar" la norma del artículo 16 del Código Civil y de esta forma aplicar por analogía el mismo principio que subyace a esta última disposición. Así, por lo demás, lo ha hecho nuestra Excma. Corte Suprema precisamente con el artículo $16^{64}$.

Por tanto, y de acuerdo con la interpretación que hemos dado al artículo 16, debemos concluir que los contratos celebrados en Chile para cumplirse en el extranjero se rigen por la ley de este último lugar. Pero también puede ocurrir que se someta al conocimiento de los tribunales chilenos un contrato que fue celebrado en un país para cumplirse en otro, ninguno de los cuales es Chile. Pues bien, a nuestro juicio, y en línea con lo que venimos planteando, corresponderá asimismo aplicar a estos casos el principio que subyace al artículo 16.

\section{LEY APLICABLE A LA FORMA DEL CONTRATO}

La forma se refiere a los requisitos externos que el acto debe observar para que la voluntad de las partes pueda tener trascendencia jurídica y es, en principio, independiente de los requisitos internos que el acto debe cumplir para su validez sustantiva.

\subsection{LA LEY IMPOSITIVA Y LA LEY REgULADORA DE LA FORMA, Y SU RELACiÓN CON LA REGLA LEX LOCUS REGIT ACTUM \\ Siguiendo a Goldschmidt, es posible distinguir en esta materia entre la ley que} impone la forma (o exime de ella) y determina las consecuencias de su omisión (ya sea la inexistencia o nulidad del acto, o bien tan solo dificultades probatorias), también denominada ley impositiva de la forma, y aquella que regula cómo dicha forma habrá de cumplirse, o ley reguladora ${ }^{65}$.

Como veremos, si bien normalmente ambas convergen en nuestro derecho en la máxima lex locus regit actum, de modo que la ley impositiva tanto como la ley reguladora corresponden a aquella donde el acto se otorga, no siempre es así, por lo que es importante tener en cuenta esta distinción.

Por último, no está de más recordar que, pese a sus términos, la regla lex locus regit actum solo se refiere a la forma del acto, mas no a su fondo. En consecuencia, esta fórmula no supone entregar a la ley del lugar de otorgamiento del acto más que la regulación de la forma extrínseca.

\footnotetext{
${ }^{64}$ Véase, por ejemplo, Banco de Tacna con Espada y Donoso Hmnos. (1930).

${ }^{65}$ Goldschmidt (1990) pp. 255 y ss. El autor agrega además la ley calificadora, es decir, aquella que juzga acerca de la equivalencia de la forma realizada con la forma exigida. Nosotros nos referiremos a esto más adelante.
} 


\subsection{REGLA LEX LOCUS REGIT ACTUM Y SU ÁMBITO DE APLICACIÓN}

En materia de formas la doctrina civilista distingue, en general, entre las formalidades de existencia o validez, la formalidades de prueba, las formalidades de publicidad y las llamadas formalidades habilitantes. Las primeras, por lo general, tienen por objeto proteger al autor del acto de la precipitación, evitándole de este modo probables perjuicios. Las segundas, favorecer la eficacia de determinados actos, sujetándolos a ciertos requisitos que permitan su constatación, asegurando con ello su prueba. Las terceras, responden usualmente al interés de terceros, quienes gracias a ellas pueden tomar conocimiento de un acto que eventualmente pudiera afectarles. Por último, están las formalidades habilitantes cuyo objeto normalmente es proteger a ciertas personas que se estiman vulnerables, exigiendo el cumplimiento de determinados requisitos para que estas personas puedan intervenir en la celebración de actos jurídicos.

Se aprecia aquí con toda claridad la distinta naturaleza y función de cada una de estas formalidades. Antes de continuar, entonces, es necesario determinar cuáles quedan comprendidas dentro del ámbito de aplicación de la lex locus y cuáles no, pues tal y como se ha señalado "No es la forma en sí, sino su función o finalidad, el criterio que inspira las respuestas normativas" del DIPr ${ }^{66}$.

En este sentido, estimamos que dado la vinculación de las formalidades habilitantes con la capacidad de las personas, estas ameritan mención aparte. En consecuencia, y siguiendo el tratamiento que estas formalidades han recibido en la doctrina comparada, no nos referiremos a ellas en este trabajo ${ }^{67}$.

En cuanto a las formalidades de publicidad, estas no consisten estrictamente en la forma del acto, ni condicionan su validez, sino que se prevén con el fin de delimitar la oponibilidad del acto o derecho frente a terceros. Por lo mismo, y en línea con lo planteado por otros autores, corresponderá a la ley aplicable a los "efectos" del acto (en nuestro caso, a la LLS como lex causae) y no a la lex locus, decidir si corresponde observar alguna formalidad de este tipo o no ${ }^{68}$. Eso sí, si esta última ley (ley impositiva) exige una determinada forma de publicidad como requisito de oponibilidad del acto frente a terceros, la ley encargada de llevarla a efecto en un país extraño no podrá ser otra que la ley de dicho país. En especial, si la forma impuesta requiere la intervención de funcionarios públicos de ese país o es derechamente desconocida allá ${ }^{69}$.

En lo que respecta a las formalidades de existencia o validez, ellas caen de lleno en la esfera de acción de la lex locus, entendida esta en su faceta impositiva y reguladora de la

\footnotetext{
66 Fernández y SÁNCHEZ (1999) p. 307.

67 FERNÁNDEZ y SÁNCHEZ (1999) p. 307.

68 FernándeZ y SÁNCHEZ (1999).

69 Puede ocurrir, así, que la forma disponible en el país extranjero no coincida exactamente con la forma exigida por la ley impositiva. En ese caso, y habida cuenta de la disociación entre una y otra, corresponderá a la ley impositiva juzgar sobre la suficiencia o equivalencia de la forma realizada en el extranjero con la forma exigida por la ley aplicable al fondo [En este sentido, Goldschmidt (1990) p. 256, para. 227]. En todo caso, lo más importante, es que la calificación se haga con un criterio verdaderamente internacional evitando proyectar localismos jurídicos que terminen por privar de eficacia a formas empleadas en el extranjero que, en definitiva, cumplen funciones y resguardan intereses análogos a los de la ley impositiva.
} 
forma. En consecuencia, la validez formal de los actos otorgados en un país extranjero se regirá por las leyes de ese país y no podrán, en general, ser impugnadas con invocación de la falta de formas o solemnidades exigidas por otras leyes.

En relación con las formalidades de prueba, en general la doctrina nacional ha estimado que ellas no caben dentro de la esfera de acción de la lex locus. Y se ha basado para ello en la nota que el redactor de nuestro código formuló al margen del primitivo artículo 13 del Proyecto de 1953, hoy artículo 18. En ella, Bello señalaba que "Los requisitos probatorios son materia de derecho público, contra el cual nada valen ni las leyes de un país extranjero, ni las convenciones privadas".

Nosotros, sin embargo, disentimos de esta posición. Si bien es cierto que las reglas en materia de prueba normalmente se rigen por la lex fori, tratándose de cuestiones que evidentemente atañen a las formas de los actos, estas quedan cubiertas por la lex locus. Tal es el caso de los artículos 1.708 a 1.711 del Código Civil.

En efecto, y como señala Rabel refiriéndose a los artículos 1.341 y siguientes del Código Civil francés (que son la fuente de las respectivas disposiciones de nuestro código), "notwithstanding some doubts in the past and isolated opposition by modern writers, the rules restricting testimony by witness in favor of written documentation generally enjoy classification as pertaining to formalities in the meaning of conflict of laws". Agrega el autor: "It is quite true that the idea of legislators drafting such provisions centers in the procedural situation of a sui ton the contract; originally they attempted to obviate perjury by bribed witnesses. But, as the French Advocate General in a learned report of 1880 remarked, in the eyes of the parties making a contract, the problem is whether they must reduce it to writing, This, however, is enough of a form problem for the purpose of the conflict of laws, despite the fact that admission of a witness is certainly a judicial act"70.

Lo contrario, de hecho, importaría traicionar la esencia misma del principio lex locus regit actum, pues no tiene ningún sentido reconocer, por una parte, la validez al acto realizado con arreglo a la forma prescrita por la ley del lugar de su otorgamiento y, enseguida, negarle eficacia probatoria.

De más está recordar, tal como dijimos previamente, que una vez promulgadas las leyes, ellas se independizan de su redactor, por lo que los comentarios de Bello no pueden estimarse vinculantes y solo constituyen un antecedentes para tomar en cuenta. En este caso, sin embargo, creemos que más y mejores razones militan a favor de nuestra posición.

En consecuencia, si el acto cumple con las formalidades que a este respecto prescribe la lex locus, no podrá por lo general desconocérsele su mérito probatorio ante los tribunales chilenos, no obstante la ley chilena exigiera la observancia de otros requisitos de orden formal para la prueba de la categoría de acto en cuestión.

\footnotetext{
70 Rabel (1958) pp. 504-505. En armonía con lo anterior, se ha señalado también que "los medios de prueba que han de servir para establecer la existencia jurídica de los contratos realizados en país extranjero, y las modificaciones que pueden haber recibido los contratos accesorios y subsiguientes, deben ser determinados con arreglo a la ley del país en donde se han verificado dichos actos y que por consiguiente debe el juez admitir la prueba testifical, cuando la ley del lugar en donde se ha verificado el contrato no exige instrumento escrito, y admite la prueba por testigos”. Véase: Fiore (1878) p. 98, para. 319. La cita, en todo caso, es de Zacarías.
} 


\subsection{FUENTE LEGAL DEL PRICIPIO LEX LOCUS}

Expuesto lo anterior, es importante notar que, en general, existe acuerdo en la doctrina y jurisprudencia nacionales en cuanto a que nuestra legislación consagra en materia de formas el principio lex locus riget actum con carácter general y amplio. No existe igual acuerdo, empero, en lo que respecta a la fuente legal de este principio. Así, mientras algunos lo fundan principalmente en el inciso segundo del artículo $16^{71}$, otros estiman que dicho principio derivaría más bien del artículo 17, en armonía con otras disposiciones análogas que lo recogerían ${ }^{72}$.

A nuestro juicio, y tal como ya hemos adelantado, este principio se desprende del inciso segundo del artículo 16, por lo que resulta del todo inoficioso acudir a otras disposiciones para fundarlo. El inciso segundo del artículo 16 entrega a la ley del lugar de celebración del contrato la regulación del mismo en sus más diversos aspectos, incluido lo referido a su forma ${ }^{73}$. Esta regla no se ve alterada cuando el contrato ha de cumplirse en Chile, a diferencia de lo que ocurre con la ley aplicable a los "efectos" del mismo, tal como los hemos entendido, toda vez que el inciso tercero precisamente excluye del ámbito de aplicación de la LLS todo lo relativo a la forma del acto al hablar de "efectos". En consecuencia, será por lo general la ley del lugar de otorgamiento o celebración del acto la que determinará si este debe observar algún tipo de forma o no, y cómo habrá de cumplirse en la afirmativa, sin importar en principio que la ley aplicable al fondo disponga de una formalidad distinta (si la hubiere).

El inciso segundo del artículo 16 consagra así con carácter general la máxima lex locus riget actum, tanto como ley impositiva como reguladora de la forma. Por eso es que decíamos previamente que manifestado el consentimiento en la "forma" establecida por la ley del lugar de otorgamiento del acto (si es que hubiera alguna) y, desde esa perspectiva, otorgado el contrato válidamente en país extraño en los términos del inciso segundo del artículo 16, el contrato estará en condiciones de producir consecuencias jurídicas, sin que deba cumplir con ulteriores requisitos formales, aun cuando haya de cumplirse en Chile y no obstante la ley chilena sí los exija para la categoría de acto de que se trate.

\subsection{EXCEPCIONES}

La regla lex locus, con todo, no es absoluta y admite diversas excepciones. Una primera excepción es la regla auctor regit actum consagrada en el artículo 17 del Código Civil que, como veremos, en ciertos casos puede oponerse a la lex locus erigiéndose de este modo como una verdadera excepción a dicho principio. Una segunda excepción, es la establecida en el artículo 18 del Código Civil que resta valor a los instrumentos privados otorgados en el extranjero, de conformidad con la lex locus, cuando la ley chilena exigiera instrumento

\footnotetext{
71 Fabres (1908) p. 199.

72 En este sentido: Domínguez (1966) p. 272; GuZmán (1989) p. 514; entre otros. Igualmente: Charles Sencom y Cia. con A.R. Fallabela y Cía. (1927) y Ferrer con Banco Español de Chile e Liquidación (1931).

${ }^{1}$ artículo 17, relativo a las formas de los instrumentos públicos, el artículo 1.027 dado a propósito de los testamentos y el artículo 80 de la ley 19.947 respecto de los requisitos de forma de los matrimonios celebrados en el extranjero.

73 En contra, Albónico (1950) p. 87.
} 
público para pruebas que hayan de rendirse en Chile. Por último, estimamos asimismo que cuando la forma exigida por la lex locus difiera de la forma exigida por la ley chilena (que puede no ser ninguna) y las partes hayan ajustado su contrato, en lo formal, a esta última ley (chilena), debe reconocerse una tercera excepción la regla lex locus regit actum ${ }^{74}$.

A continuación nos referiremos a cada una de estas excepciones por separado.

\subsubsection{La regla auctor regit actum}

En nuestra opinión, el artículo 17 del Código Civil consagra en Chile la regla auctor regit actum, según la cual las solemnidades de los instrumentos públicos se rigen por la ley que regula la actividad de la autoridad interviniente, y no la lex locus regit actum, ya reconocida con carácter general en el inciso segundo de la norma precedente. Así se desprende, a nuestro juicio, de la génesis de esta disposición, y de su interpretación sistemática.

En efecto, el origen de este artículo según las propias notas de Bello es el inciso primero del artículo 10 del código de Luisiana. Dicha disposición, aunque muy similar en su redacción al artículo 17 de nuestro Código Civil, no solo hacía referencia a los instrumentos públicos sino también a los instrumentos privados. Igual alcance recogía el artículo 10 del Proyecto de Código de García Goyena, el que también ha sido citado por la doctrina nacional como fuente de inspiración de Bello ${ }^{75}$. El artículo 17, sin embargo, solo alude a los instrumentos públicos.

Pues bien, para aquellos que sostienen que esta disposición no es más que una reiteración de la regla lex locus en materia de instrumentos, la ausencia de toda referencia a los instrumentos privados resulta inentendible, pues todos coinciden que la lex loci también rige tratándose de instrumentos privados ${ }^{76}$. Es por esto que a fin de salvar el argumento se han intentado varias explicaciones.

\footnotetext{
${ }^{74}$ De otra parte, no consideramos que el artículo 420 No 5 del Código Orgánico de Tribunales constituya una excepción a la regla lex locus. De acuerdo con esta disposición, "Una vez protocolizados, valdrán como instrumentos públicos", entre otros, "Los instrumentos otorgados en el extranjero, las transcripciones y las traducciones efectuadas por el intérprete oficial o los peritos nombrados al efecto por el juez competente y debidamente legalizadas, que sirvan para otorgar escrituras en Chile”. Más allá de la desafortunada dicción e incluso ubicación de esta norma, creemos que ella solo tiene por propósito establecer un requisito de orden registral para que los instrumentos otorgados en el extranjero puedan servir de base para otorgar escrituras públicas en nuestro país. En caso alguno, podría estimarse que esta norma priva del carácter de público o privado al instrumento extranjero para los efectos que interesan a la regla lex locus, mientras no se protocolice. A esta conclusión, por lo demás, parece haber llegado también la Excma. Corte Suprema, quien ha fallado que "la protocolización exigida por el No 5 del artículo 420 del Código Orgánico de Tribunales, solo es necesaria cuando el documento, además de otorgarse en el extranjero, haya servido para otorgar escrituras públicas en Chile, requisito -este último- exigido con el evidente propósito de asegurar a los otorgantes de la escritura pública y a los terceros interesados en su examen, el conocimiento directo del instrumento expedido fuera del país, que le ha servido de antecedentes" Wulle-Herb, Margherite con Fisco (1954). En el mismo sentido: Galletti, Margarita con Lagos, Elvira (1954).

75 Véase: Fabres (1908) p. 196. De acuerdo con el artículo 10 del Código de García Goyena, "Las formas y solemnidades de los contratos, testamento y de todo instrumento público

76 Además, tampoco hace sentido que se excluya del ámbito de regulación de la lex loci los actos informales, pues uno de los propósitos de esta regla es, precisamente, garantizar la eficacia de estos actos cuando la lex loci ningún requisito de orden formal exige pero sí lo hace la lex causae.
} 
Así, algunos han sugerido que la referencia a los instrumentos privados sería innecesaria toda vez que, en razón de la propia naturaleza de estos instrumentos, ningún requisito de orden formal deben cumplir.

Este argumento, sin embargo, no es correcto. Muchas legislaciones exigen a los instrumentos privados (o a determinados instrumentos privados en función del acto que en ellos consta) que estén, por ejemplo, firmados, datados, o que empleen fórmulas sacramentales en su redacción, o bien que dispongan de algún tipo de estampillas, entre otras exigencias, todas ellas de orden formal.

Otros, por su parte, sostienen que la referencia a los instrumentos privados en el artículo 17 sería innecesaria, toda vez que la regla lex locus ya está consagrada con carácter general en el inciso segundo del artículo $16^{77}$.

Nosotros, si bien coincidimos con esto último, no podemos dejar de notar que semejante explicación tornaría totalmente redundante al artículo 17, además de caprichoso (por excluir sin motivo alguno a los instrumentos privados). Esto, por supuesto, salvo que se nos conceda, como de alguna manera también ha sugerido Guzmán ${ }^{78}$, que el artículo 17 no tiene por propósito reiterar la regla lex locus, sino consagrar la regla auctor regit actum, la cual solo concierne a los instrumentos públicos. He ahí la razón por la cual la norma nada dice respecto de los instrumentos privados.

Así, de acuerdo con esta regla, cada vez que el otorgamiento de un instrumento requiera la participación de una autoridad pública de un determinado Estado, las solemnidades del instrumento se regirán por la ley que rija la actividad de dicha autoridad ${ }^{79}$.

Ahora bien, la regla general es que los fedatarios públicos actúen dentro de los límites territoriales del Estado que les confiere esa potestad, por lo que la regla lex locus tenderá a coincidir con la regla auctor regit actum. Así ocurrirá, por ejemplo, cada vez que en el acto intervengan notarios u oficiales del registro civil chilenos. Obviamente, aquí ninguna excepción al principio lex locus tendrá lugar.

Sin embargo, hay autoridades chilenas que están expresamente facultadas para intervenir en el otorgamiento de actos en el extranjero, y cuando lo hacen, se arreglan al derecho chileno, no al derecho del lugar de otorgamiento. Es precisamente en esta hipótesis, en la que el artículo 17 se erige como una verdadera excepción la regla lex locus, autorizando el otorgamiento de un acto de acuerdo con las formas establecidas por la ley chilena y no por la ley del lugar de otorgamiento.

Así ocurre, por ejemplo, con las facultades que el Reglamento Consular confiere a los funcionarios consulares chilenos en el extranjero para actuar como notarios y ministros de fe de conformidad a las leyes chilenas (y no extranjeras), en los actos que ya sea chilenos o extranjeros otorguen ante ellos en el exterior.

Nótese que si siguiéramos la interpretación que la mayoría de la doctrina y jurisprudencia nacionales ha dado tradicionalmente al artículo 17 (según la cual esta disposición

\footnotetext{
77 Así, por ejemplo, Fabres (1908) p. 199.

78 GUZMÁN (1989) pp. 515 y ss.

79 No podría ser de otro modo ya que las autoridades públicas de cada país actúan dentro del marco de su propia organización institucional y en virtud de su exclusiva legislación, por lo que no pueden extender, autorizar $\mathrm{u}$ otorgar instrumentos con las solemnidades de una ley distinta.
} 
no hace más que reiterar el principio lex locus en materia de instrumentos públicos), habría que concluir que las facultades que el referido reglamento -que no tiene rango legal- otorgan a los funcionarios consulares son derechamente ilegales, al oponerse a artículo 17 (interpretado del modo que lo hace dicha doctrina), ni poder constituir válidamente una excepción a él, dado su rango infra legal.

Es cierto que el artículo 17 del Código Civil habla de la ley del país en que hayan sido otorgados los instrumentos públicos, sin aludir expresamente en su texto a la ley del funcionario interviniente. Sin embargo, creemos que esta referencia debe entenderse implícita en la norma, desde que, como dijimos, en la inmensa mayoría de los casos la ley del país en que el instrumento público se otorga y la ley del funcionario que interviene coincidirán, de suerte que la falta de precisión de esta norma bien puede explicarse por esta circunstancia, sin alterar su espíritu.

En consecuencia, cada vez que el funcionario interviniente actúe dentro del territorio de su jurisdicción, el artículo 17 operará, en los hechos, como una mera reiteración de la regla locus regit actum y ninguna excepción a este principio tendrá lugar. Pero si el funcionario interviniente, en cambio, actúa fuera de los límites de su territorio, en virtud de una normativa que lo habilita para ello, la regla auctor contenida en el artículo 17 recién citado actuará como una verdadera excepción a la lex locus, toda vez que, en definitiva, el acto se otorgará ya no conforme a la leyes de dicho lugar, sino conforme a la ley de un tercer país (en este caso Chile).

\subsubsection{Cuando las leyes chilenas exigieren instrumentos públicos para pruebas que} han de rendirse y producir efecto en Chile

Una segunda excepción a la regla locus regit actum es la contenida en el artículo 18 del Código Civil, según el cual cuando las leyes chilenas "exigieren instrumentos públicos para pruebas que han de rendirse y producir efecto en Chile no valdrán las escrituras privadas, cualquiera que sea la fuerza de estas en el país en que hubieren sido otorgadas". En otras palabras, cuando la ley chilena exigiera instrumento público para el otorgamiento de determinados actos, no obstante estos actos hayan sido otorgados en el extranjero, en donde ellos según la ley de dicho lugar (lex loci) no están sujetos a formalidad alguna o bien basta que consten en instrumento privado, deberán otorgarse por instrumento público, si así lo exigiere para esa categoría de actos la ley chilena y hubieran de ser presentados en juicio en Chile.

Al tratar esta materia, la mayoría de la doctrina nacional -siguiendo a Fabres nuevamente- ha estimado que el artículo 18 no constituye verdaderamente una excepción al principio lex locus, toda vez que el artículo 18 se ocuparía más bien de una cuestión diversa, cual es, la fuerza probatoria de los instrumentos otorgados en el extranjero y no propiamente de las formalidades del acto ${ }^{80}$.

Como ya dijimos, sin embargo, en materia de formas no solo existen las formalidades de existencia o validez, sino también las de prueba, y estas también vinculan la eficacia del acto con la observancia de ciertos requisitos de orden formal. Así, no cabe duda que el

${ }^{80}$ Fabres (1908) pp. 211 y ss.; Claro Solar (1978) p. 116; Domínguez (1966) p. 275; Guzmán (1989) p. 517; entre otros. 
artículo 18 sí constituye una excepción a la regla lex locus, desde que niega eficacia a actos otorgados en el extranjero conforme a dicha legislación, obligándolos a constar por instrumento público cuando así lo exige la ley chilena.

Ahora bien, resta por determinar cuáles son los casos en que las leyes chilenas exigen instrumentos públicos y a los cuales se refiere el artículo 18 antes citado. En este sentido, debemos descartar que estos casos correspondan a cuando el acto se otorga en Chile, pues en esta hipótesis el acto debe observar las formalidades dispuestas en la ley chilena a consecuencia de lo previsto en el inciso segundo del artículo 16, y no del artículo 18. En otras palabras, rige aquí en plenitud la regla lex locus y ninguna excepción tiene lugar.

El artículo 18 entonces se refiere, a nuestro entender, a casos en los cuales el acto se otorga en el extranjero pero para cumplirse en Chile, de modo que la ley chilena rige a título de lex causae, desconociendo cualquier mérito a la lex locus cuando el acto ha debido constar en instrumento público según la ley chilena. Si, por el contrario, el acto no se otorga en Chile ni ha de cumplirse y producir efectos en nuestro país, estimamos que, aun cuando el acto sea sometido al conocimiento de los tribunales chilenos (porque, por ejemplo, el demandado tiene su domicilio en Chile), nada podrá la ley chilena disponer a este respecto. El acto, por lo demás, ningún contacto relevante con Chile tendrá, por lo que mal podría exigírsele a las partes que en él han intervenido prever la aplicación de la ley chilena.

En suma, cuando un acto deba constar en instrumento público conforme a la ley chilena, no obstante se hubiere otorgado en el extranjero, si ha de servir de base para pruebas que hayan de rendirse y producir efectos en Chile, la regla lex locus no tendrá aplicación. Eso sí, la calificación que a este respecto haga el intérprete debe guiarse por un criterio internacional, de modo de evitar proyectar localismos jurídicos que terminen por privar de eficacia a formas empleadas en el extranjero que, en definitiva, cumplen funciones y resguardan intereses análogos a los de la ley impositiva ${ }^{81}$.

\subsubsection{Casos en que la ley extranjera exija el cumplimiento de cierta formalidad, no} asi la ley chilena en calidad de LLS

Queda, por último, por determinar cuáles son las consecuencias que se siguen si el acto se otorga en el extranjero y no cumple con la formalidad exigida por la ley extranjera, pero sí cumple con la ley chilena en calidad de lex causae, ya sea porque la ley chilena ningún requisito formal establece para esa categoría de actos o bien porque la formalidad observada por el acto es suficiente desde el punto de vista de la ley chilena.

A nuestro juicio, en estos casos debe reconocerse una tercera excepción al principio lex locus regit actum. En efecto, más allá de cuál fue la intención original del legislador al establecer esta regla en el inciso segundo del artículo 16 del Código Civil, lo cierto es que desde el momento en que la ley chilena permite tanto a nacionales como extranjeros otorgar sus actos en el exterior ajustándose en lo formal a las leyes chilenas, como ocurre con los actos autorizados por funcionarios consulares chilenos, y les reconoce además efectos en Chile con independencia de lo que disponga la lex locus, queda claro, a nuestro juicio, el

81 Con notable criterio: Corte de Apelaciones de Concepción (1934) p. 453. 
carácter alternativo con el que ordenamiento jurídico concibe esta regla, a lo menos cuando la lex causae es la ley chilena ${ }^{82}$.

En otras palabras, las partes pueden obviar cumplir con la formalidad del lugar de otorgamiento del acto, en tanto su acto se ajuste en lo formal a la ley chilena (que puede no establecer formalidad alguna para el acto en cuestión).

Esta posición, además, es plenamente consistente con la tendencia en el derecho comparado y con la propia justificación de la citada regla, cual es, según la visión predominante, facilitar y resguardar la eficacia formal de los actos ${ }^{83}$, asumiendo que para concertar un contrato válido o eficaz las partes tienen mayor facilidad para consultar la ley local ${ }^{84}$. Pero, en ningún caso, les prohíbe ajustar su acto a la ley aplicable al fondo.

\section{DETERMINACIÓN Y CONCRECIÓN DE LAS CONEXIONES EMPLEADAS POR LAS NORMAS DE CONFLICTO DEL CÓDIGO CIVIL}

Dado las consecuencias que tanto el lugar de celebración del contrato como el lugar de cumplimiento importan como criterios de conexión escogidos por nuestro legislador, debemos detenernos aquí a precisar la manera como han de determinarse o, más propiamente, concretarse estas conexiones.

Surge aquí de inmediato una primera dificultad, toda vez que ambas conexiones parecen partir de la base de que un contrato ha sido efectivamente concluido, en circunstancias que, como todos sabemos, bien puede una de las partes controvertir este hecho.

En general, la solución que ha dado la doctrina comparada a estos casos pasa por utilizar la respectiva conexión asumiendo que un contrato ha sido efectivamente celebrado (locus hypothetici contractus) $^{85}$. Se recurre así al lugar de celebración o cumplimiento del presunto contrato, sin importar que su existencia pueda ser objeto de debate. Eso sí, una vez determinada de este modo la lex contractus, la lex fori cederá paso y el contrato deberá examinarse a la luz de la ley aplicable, incluido todo lo relacionado con su celebración y cumplimiento. Por tanto, la lex fori solo tendrá relevancia para concretar la conexión y determinar de esta manera la lex contractus. De ahí en adelante, todo lo que concierne al contrato quedará entregado a esta última.

La solución puede parecer un tanto artificiosa. En especial, porque pueden darse situaciones en la cuales, de acuerdo con la lex fori exista un contrato para efectos de determinar el lugar de celebración o cumplimiento, y no de acuerdo con la ley que en definitiva

\footnotetext{
82 GuZMÁn participa de esta opinión. Sin embargo, limita el alcance de esta excepción únicamente a los documentos públicos, mas no a los privados. Respecto de estos últimos, la regla lex locus es para él imperativa. Véase: GuZMÁn (1989) p. 516.

83 Véase: Feldstein (2000) pp. 265-270. La autora cita una larga lista de autores que dan cuenta que la visión que prima entre ellos es esta y concluye señalando, además, que hoy día la mayoría está con el carácter facultativo de la regla lex locus.

${ }^{84}$ Muchas veces, dice Savigny, es difícil conocer, en el lugar donde el acto se otorga, las formas legales exigidas por la ley de aquel en que el acto debe producir sus efectos, y mucho más difícil el observarlas por completo. Por eso para evitar privar de eficacia a los actos jurídicos otorgados en el extranjero por falta de formas legales se justifica el lex locus.

${ }^{85}$ Virgos Soriano (1989) p. 32.
} 
es aplicable. Habría sido mejor, quizás, que el legislador hubiere escogido una conexión distinta. Sin embargo, una vez que el legislador ha escogido esta conexión, la solución pasa por esta vía, tal como lo ha reconocido la doctrina comparada ${ }^{86}$.

Por otra parte, existe bastante consenso en el sentido que corresponde a la lex fori concretar la conexión que utiliza la norma de conflicto ${ }^{87}$. Para ello, y tratándose de conexiones que se refieren al fondo del asunto (como es el caso del lugar de celebración y el lugar cumplimiento), la doctrina parece estar de acuerdo en integrar la conexión con el contenido que le otorga el propio ordenamiento jurídico a la cual pertenece, y con independencia de la ley que en definitiva resulte aplicable. De esta forma, se consigue una interpretación uniforme de los criterios de conexión, evitando que su concreción se vea alterada por el derecho al cual dirige la norma de conflicto.

Eso sí, los mismos autores que abogan por esta solución advierten que al integrar de este modo la norma de conflicto no debe olvidarse que los valores e intereses en juego, así como los objetivos de política legislativa perseguidos, no son necesariamente los mismos, por lo que deben hacerse los ajustes necesarios al interpretar y aplicar la norma ${ }^{88}$.

\subsection{LUGAR DE CELEBRACiÓN}

Tratándose de contratos entre presentes, la determinación del lugar de celebración no pone mayores dificultades. Este será fácilmente identificable.

Distinta es la situación, en cambio, en los contratos entre ausentes. En ellos no existe verdaderamente "un lugar" de celebración, de suerte que toda alusión a este lugar no es más que una ficción jurídica.

Dicho esto, es importante notar que, a diferencia de lo que ocurre en otros países, la ley chilena cuenta con una norma que se encarga, precisamente, de determinar el lugar de celebración del contrato cuando este ha sido concluido a distancia. Así, de acuerdo con el artículo 104 del Código de Comercio "Residiendo los interesados en distintos lugares, se entenderá celebrado el contrato, para todos sus efectos legales, en el de la residencia del que hubiere aceptado la propuesta primitiva o la propuesta modificada”. Nótese que la norma no localiza el contrato en el lugar donde se dio la aceptación sino en el de la "residencia" del aceptante, que bien pueden no coincidir.

No obstante la ubicación de esta norma en el Código de Comercio, la doctrina nacional está de acuerdo en que su alcance no se restringe al ámbito mercantil sino que es de aplicación general ${ }^{89}$. Así, por cierto, lo deja en claro el propio Código de Comercio en el mensaje con el cual se acompañó el Proyecto al Congreso. Nosotros, además, no dudamos en calificar esta norma como una de derecho internacional privado ${ }^{90}$.

Ahora bien, a nuestro juicio el artículo 104 del Código de Comercio no es imperativo sino que solo presume legalmente que el lugar de celebración en los contratos entre

\footnotetext{
86 Virgos Soriano (1989) p. 41.

87 Virgos Soriano (1989) pp. 15 y ss.

88 Virgos Soriano (1989) pp. 20-21.

89 SAndoval (1972) p. 19.

90 En contra, aunque sin dar mayores explicaciones: AlbónICO (1972) pp. 29-32.
} 
ausentes corresponde al lugar de la residencia del aceptante. Esta presunción, por lo mismo, admite prueba en contrario, pudiendo ser desvirtuada si las partes demuestran que algún otro lugar representa mejor el lugar donde el contrato debe entenderse celebrado. Así, corresponderá en definitiva al juez que conozca del asunto apreciar las particularidades del caso y determinar si concurren circunstancias que, alegadas y probadas por una o cualquiera de las partes, tengan la entidad suficiente para desvirtuar la presunción en favor de la residencia del aceptante como lugar de celebración del contrato.

Esta solución, además, tiene la virtud de dar al juez y las partes la necesaria flexibilidad en la concreción del punto de conexión "lugar de celebración", de modo que se ajuste fielmente a las circunstancias particulares del caso, pero respetando, eso sí, la decisión de nuestro legislador en torno a esta conexión ${ }^{91}$.

Ahora bien, lo señalado hasta aquí aplica únicamente a los contratos consensuales; es decir, a aquellos que no están sujetos a formalidades como requisitos para su "validez" ni su perfección está supeditada a la entrega de la cosa sobre la cual versan.

En cambio, en el caso de los contratos solemnes así como los contratos reales, no basta con el acuerdo de voluntades para darles nacimiento sino que es necesario el otorgamiento de la formalidad exigida, en los primeros, y la entrega de la cosa, en los segundos. En consecuencia, en estos casos el lugar de celebración se confundirá con el lugar en el cual estos actos se verifiquen, con independencia de lo dispuesto en el artículo 104 del Código de Comercio.

\subsection{Lugar DE CUMPLimiento}

Como vimos en la parte introductoria del presente trabajo, el lugar de cumplimiento ha sido ya desde hace muchos años un criterio de conexión habitualmente empleado en el derecho internacional privado para designar la ley aplicable al contrato.

Tratándose de contratos unilaterales, en los cuales tan solo una de las partes tiene a su cargo la ejecución de la prestación debida, este criterio de conexión no pone mayores dificultades. Bastará, por tanto, con determinar el lugar de ejecución de esa única obligación, ya sea a partir del pacto expreso de las partes, o bien acudiendo en su defecto al artículo 1558 del Código Civil (el cual, como adelantamos, integra a estos efectos la norma de conflicto). Según esta disposición "Si no se ha estipulado lugar para el pago y se trata de un cuerpo cierto, se hará el pago en el lugar en que dicho cuerpo existía al tiempo de constituirse la obligación. (...) Pero si se trata de otra cosa se hará el pago en el domicilio del deudor”.

Es decir, en primer lugar habrá que estarse a lo que hayan acordado las partes ${ }^{92}$. En seguida, si las partes nada han dicho, corresponde distinguir si la cosa debida es un cuerpo cierto o no. Si lo es, el contrato deberá cumplirse en el lugar en el cual se encuentre al tiempo de constituirse la obligación. De lo contrario, rige la regla general y, en consecuen-

\footnotetext{
91 A diferencia de otros autores que, en aras a introducir una mayor cuota de flexibilidad a nuestro DIPr, llegan al extremo de desentenderse de las conexiones escogidas por nuestro legislador, sustituyéndolas por criterios que poco o nada de sustento tienen en nuestra legislación. Véase: Siebel (1934) pp. 41 y ss., y Villaroel y Villaroel (1990) pp. 251 y ss.

92 En este sentido, de particular relevancia pueden ser los INCOTERMS en materia de compraventa internacional.
} 
cia, el lugar de cumplimiento será el domicilio del deudor al momento de celebrarse el contrato ${ }^{93}$.

Por último, es importante reiterar que la determinación del lugar de cumplimiento conforme a la lex fori es solo para efectos de dilucidar la ley aplicable al contrato. De ahí que, si una vez determinada la ley aplicable surge una controversia en relación, por ejemplo, con el lugar donde estas deben llevar a cabo los actos de ejecución del contrato, la respuesta deberá darla la lex contractus, sin que tenga incidencia la lex fori.

\subsubsection{Teoría de la prestación característica}

Queda todavía por determinar qué es lo que ocurre con el lugar de cumplimiento en los contratos sinalagmáticos.

Claro está que el artículo 1588 del Código Civil se refiere, en principio, al cumplimiento de las obligaciones, individualmente consideradas y no al contrato en su globalidad. En consecuencia, más de alguno podría pensar que, tratándose de contratos sinalagmáticos cada obligación quedará regida por la ley del lugar de su propio cumplimiento, sin importar que esto lleve a aplicar la ley de dos o más Estados distintos.

Sin embargo, esta postura en pos del fraccionamiento del contrato, si bien tuvo algo de acogida en la jurisprudencia suiza y alemana de comienzos del siglo pasado ${ }^{94}$, y cuenta en Chile además con la venia de los hermanos Villaroel ${ }^{95}$, ha sido abandonada en prácticamente todos los países que alguna vez la utilizaron, a raíz de los problemas que trae aparejados ${ }^{96}$. En efecto, y tal y como denunció hace ya varias décadas el maestro Rabel, un contrato bilateral no puede ser dividido en dos o más obligaciones unilaterales sin violentar la naturaleza misma del sinalagma ${ }^{97}$.

En vista de esto, y para evitar las odiosas consecuencias de la escisión de contrato, la doctrina suiza desarrolló en la primera mitad del siglo pasado lo que hoy en día se conoce como la teoría de la prestación característica ${ }^{98}$. Según ella, en los contratos sinalagmáticos con lugares de cumplimiento sometidos a legislaciones diferentes hay que atenerse al lugar de cumplimiento de la prestación que, por su jerarquía dentro de la dinámica del contrato, resulta verdaderamente relevante para efectos de localizarlo en el espacio. Esta, por lo general, corresponderá a la prestación no dineraria (Nicht-Geldleistung), pues es esta la que diferencia y "caracteriza", en definitiva, cada contrato, ya que el "pago del precio" es una prestación común a muchos contratos. Así, por ejemplo, en un contrato de compraventa así como en uno de arrendamiento, la prestación característica será la entrega de la cosa vendida o arrendada, y no el pago del precio o la renta.

\footnotetext{
93 Véase al efecto el artículo 1.589. Asimismo, tratándose de contratos de compraventa mercantil es útil tener presente que, de conformidad con el artículo 148 del Código de Comercio, cuando señala que "El envío de las mercaderías hecho por el vendedor al domicilio del comprador o a cualquiera otro lugar convenido, importa la tradición efectiva de ellas".

94 Rabel (1958) pp. 469-472. Véase también Carrascosa (2003) para. 17 y 24.

95 Villaroel y Villaroel (1990) p. 363.

96 Rabel (1958) pp. 469-472.

97 Rabel (1958) pp. 471-472. En el mismo sentido: Virgos Soriano (1989) p. 45.

98 Seguimos aquí a: Carrascosa (2003) para. 39 y ss.
} 
Ahora bien, en sus inicios esta teoría abogaba por la aplicación de la ley del país en donde físicamente se ejecutaba la prestación característica ${ }^{99}$. Posteriormente, sin embargo, la doctrina y jurisprudencia suizas optaron por la aplicación de la ley del país de la sede del prestador característico ${ }^{100}$.

Es así como la versión más moderna de esta teoría postula hoy en día que el contrato está anclado intrínsecamente en el país donde desarrolla su función económica y social, y dicho país no es otro que el de la sede del prestador característico. En consecuencia, es ese el lugar de cumplimiento relevante para la determinación de la ley aplicable al contrato, sin importar que en el caso particular el contrato se haya cumplido en un lugar distinto. En consecuencia, el contrato se rige, a falta de elección de Ley por los contratantes, por la Ley del país de la sede o residencia habitual del prestador que debe cumplir la obligación característica ${ }^{101}$.

A nuestro juicio, esta teoría es perfectamente aplicable en Chile a la luz de los artículos 16 y 1558 del Código Civil. En efecto, el propio texto del artículo 16 da pie para su aplicación, toda vez que pone el énfasis en el lugar de cumplimiento del contrato, considerado este como un todo. Así, son "los contratos otorgados en país extraño para cumplirse en Chile" los que se rigen por la ley chilena, no las obligaciones individualmente consideradas. Por su parte, el artículo 1558 dispone como regla general que el lugar de cumplimiento es el del domicilio del deudor, quien en este caso sería el de la prestación característica.

Refuerza esta idea, lo señalado anteriormente en orden a que una correcta interpretación del artículo 16 demuestra que el sentido de dicha norma jamás fue romper con la unidad del contrato, por lo que la teoría de la prestación característica, que precisamente busca salvaguardar esta unidad, resulta perfectamente consistente con el sentido y espíritu de esta norma.

Ahora bien, existen contratos en los cuales difícilmente podría identificarse una prestación característica. Es el caso, por ejemplo, de los contratos de permuta. Otro tanto ocurre con contratos que, en estricto rigor, no implican un mero intercambio de cosas o servicios por dinero ${ }^{102}$. En fin, las hipótesis pueden ser varias ${ }^{103}$.

A nuestro juicio, en estos casos mal podría decirse que el lugar de celebración del contrato difiere del lugar de su cumplimiento, si este último no ha podido determinarse. Por lo mismo, la solución no puede ser otra que retornar al inciso segundo del artículo 16 y utilizar como punto de conexión el lugar de celebración del contrato. Así, cada vez que sea imposible determinar un lugar de cumplimiento, conforme hemos señalado, el inciso

\footnotetext{
99 En este sentido, también: Goldschmidt (1990) p.

100 En este sentido, también: Boggiano (2000) p. 697.

101 Esta teoría, a su vez, tiene un fuerte trasfondo económico, pues conduce a la aplicación del Derecho del país en el que normalmente opera el prestador característico. Es por esto, que sus defensores sostienen que la aplicación de esta teoría incentiva a este prestador a la contratación internacional, ya que favorece la aplicación de su propia Ley, con la que está habituado a contratar, reduciendo con ello los gastos y en definitiva los precios de sus productos, ya que evita tener que incurrir en costos para poder conocer la ley de los lugares donde comercia. En buenas cuentas, se logra una estandarización de sus operaciones.

102 Carrascosa (2005) para. 14.

103 Para una relación de contratos que carecen de algún modo u otro de prestación característica, puede consultarse: Calvo Caravaca y Carrascosa (2012) pp. 690 y ss.
} 
segundo del artículo 16 proporcionará una solución por la vía de sujetar el contrato a la ley del lugar de su celebración.

\section{ALCANCE DE LA REGULACIÓN DEL CONTRATO}

Como vimos, de acuerdo con el artículo 16 del Código Civil, en general, lo que respecta a la forma del contrato se rige por la lex locus, mientras que lo que concierne al fondo del mismo queda entregado a la LLS.

Ya nos referimos al alcance de la lex locus en relación a la forma del contrato. Por lo mismo, no ahondaremos más en ello. En cambio, no nos hemos referido con igual detalle al alcance de la LLS. Esa será nuestra tarea a continuación.

\subsection{El artículo 113 del Código de Comercio}

Antes de continuar, y atendido lo señalado hasta aquí, es preciso determinar cuál es el alcance que debe atribuirse al artículo 113 de Código de Comercio.

De acuerdo con esta disposición, "Todos los actos concernientes a la ejecución de los contratos celebrados en país extranjero y cumplideros en Chile son regidos por la ley chilena, en conformidad a lo que se prescribe en el inciso final del artículo 16 del Código Civil. (...) Así la entrega y pago, la moneda en que este deba hacerse, las medidas de toda especie, los recibos y su forma, las responsabilidades que imponen la falta de cumplimiento o el cumplimiento imperfecto o tardío, y cualquiera otro acto relativo a la mera ejecución del contrato deberán arreglarse a las disposiciones de las leyes de la República, a menos que los contratantes hubieren acordado otra cosa".

En principio, esta norma pareciera tomar partido por una interpretación que no se condice ni con nuestra interpretación del alcance del artículo 16 del Código Civil, ni con la que ha mantenido durante décadas la doctrina tradicional. Más bien, e interpretado restrictivamente, el artículo 113 apuntaría a una lectura del artículo 16 muy similar a la doctrina defendida a mediados del siglo XIX por Jean Jacques Gaspard Foelix en Francia ${ }^{104}$ y propugnada a comienzos del siglo pasado por Joseph Beale en EE.UU. ${ }^{105}$, quien fuera además autor del Restatement (First) on Conflicts of Laws de $1934^{106}$.

104 De hecho, es notable el parecido entre el artículo 113 del Código de Comercio y la propias palabras de M. Foelix, quien tuvo gran influencia, a lo menos, en Francia, España y Sudamérica. En efecto, el autor señala en su obra "Traité du droit international privê", publicada por primera vez en Francia en 1843 y en España en 1860, que “(...) cuando, según la naturaleza del acto, ó según la ley del lugar del contrato, ó, en fin, según la determinación de las partes el acto debe ejecutarse en otro lugar aquel en que se perfeccionó, todo lo que concierne al cumplimiento de las obligaciones contraídas en el contrato y su ejecución, en otros términos, todo lo que debe hacerse después de celebrado el contrato, se rige por la ley de este lugar. Así esta ley determinará las formalidades de la entrega y del pago, la medida de las tierras o los objetos muebles enajenados, la moneda en que debe efectuarse el pago, la obligación de dar finiquito, la morosidad y la obligación al resarcimiento de intereses que lleva consigo" Foelix (1960) p. 167.

105 Véase Beale (1909) p. 1 y ss.

106 Así, la sección 332 del First Restatement señala que "The law of the place of contracting determines the validity and effect of a promise with respect to (a) capacity to make the contract; (b) the necessary form, if any, in which the promise must be made; (c) the mutual assent or consideration, if any, required to make a promise binding; (d) any other requirements for making a promise binding; (e) fraud, illegality, or any other circumstances which make 
Bajo esta óptica, el contrato, y por cierto los derechos y obligaciones que de él nacen, estarían sujetos a la LLC, con exclusión solo de aquellas cuestiones listadas en el artículo 113 recién citada y que dicen relación con la mera ejecución de los derechos y obligaciones contractuales. Estos, y no otros aspectos del contrato, quedarían regulados por la ley del lugar de cumplimiento, si este corresponda a Chile.

No conocemos, sin embargo, autor que haya postulado alguna vez en nuestro país una interpretación como esta en relación con los incisos segundo y tercero del artículo 16. Por el contrario, y como vimos, la doctrina nacional ha interpretado siempre el artículo 16 con un alcance bastante más amplio que el que podría atribuírsele sobre la base de esta lectura del artículo 113 del Código de Comercio, sujetando no solo la ejecución de los derechos y obligaciones a la LLS, sino que todo cuanto concierne a estos, excluyendo (o creyendo excluir) únicamente las cuestiones de validez del contrato.

Cualquiera sea el caso, lo cierto es que, a nuestro juicio, una interpretación restrictiva del artículo 16, como la que venimos examinando, debe ser rechazada. Y debe serlo, por varios motivos.

En primer lugar, ya hemos demostrado que el sentido y alcance del artículo 16 y, en particular, de su inciso tercero, es el de consagrar en Chile la vigencia de la LLS en todo cuanto respecta al fondo del contrato, cuando este haya de cumplirse en un lugar distinto de aquel en donde se celebró. No cabe duda que, cualquiera sea el sentido que se atribuya al artículo 113 del Código de Comercio, esta norma no es una ley interpretativa que pudiera alterar sin más el sentido y alcance del artículo 16 recién referido.

En segundo lugar, interpretar el artículo 113 del Código de Comercio de modo inconsistente con el artículo 16 recién citado, importaría sostener que en Chile existe una dualidad de regímenes en materia de ley aplicable a los contratos internacionales: uno respecto de los contratos civiles y otro distinto para los contratos mercantiles ${ }^{107}$. Es evidente que tal resultado no resulta, en absoluto, satisfactorio. No por nada la doctrina comparada ha hecho siempre grandes esfuerzos por interpretar las normas de conflicto, de modo de mantener la unidad de las soluciones y evitar distinciones vinculadas a la naturaleza civil o comercial del acto ${ }^{108}$.

En tercer lugar, los propios autores norteamericanos se han encargado de denunciar las múltiples falencias e inconvenientes de separar las cuestiones de validez con aquellas re-

a promise void or voidable; $(f)$ except as stated in $\$ 358$, the nature and extent of the duty for the performance of which a party becomes bound; $(g)$ the time when and the place where the promise is by its terms to be performed; ( $h$ ) the absolute or conditional character of the promise". La sección 358, sin embargo, aclara que "The duty for the performance of which a party to a contract is bound will be discharged by compliance with the law of the place of performance of the promise with respect to: (a) the manner of performance; (b) the time and locality of performance; (c) the person or persons by whom or to whom performance shall be made or rendered; (d) the sufficiency of performance; (e) excuse for non-performance".

107 Es importante notar que, a diferencia de lo señalado a propósito del lugar de celebración del contrato, el mensaje del Código de Comercio no da ninguna pista que pudiera servir para sostener que el artículo 113 es de aplicación general.

108 Virgos Soriano (1990) p. 100. El autor hace énfasis en que uno de los propósitos de la reforma del año 1974 al Código Civil español, en materia de DIPr, fue precisamente suprimir cualquier distinción vinculada al carácter mercantil o civil del acto en lo que respecta a la determinación del derecho aplicable. 
lativas a la ejecución de las obligaciones del contrato a fin de determinar la ley aplicable al mismo (y, por ende, de interpretar de este modo el artículo 113 del Código de Comercio). Tanto así, que el First Restament cayó en desgracia al poco tiempo de ser publicado y fue definitivamente reemplazado en 1971 por el Second Restament.

Por cierto, las mismas razones aducidas por los autores norteamericanos para refutar la doctrina del First Restatement abogan, a nuestro juicio, por el rechazo de una interpretación del artículo 113 que traiga como consecuencia la restricción de la esfera de acción de la LLS a las meras cuestiones de la ejecución, conforme lo señalado. Dentro de estas razones, está la imposibilidad práctica de trazar una verdadera línea divisoria entre las cuestiones que atañen a la ley del lugar de celebración y aquellas que quedan entregadas a la ley del lugar de cumplimiento ${ }^{109}$; la inexistencia de precedentes judiciales en dicho país que avalen la doctrina del Restatement y, por tanto, su viabilidad real ${ }^{110}$; las intrincadas implicancias de esta doctrina en relación con la determinación de la legalidad del acto ${ }^{111}$, etc.

En suma, todas estas razones determinan a nuestro juicio que el artículo 113 del Código de Comercio deba interpretarse de manera consistente con el sentido y alcance que hemos dado al artículo 16. Esto fuerza a concluir que el inciso segundo del citado artículo 113 contiene una lista no exhaustiva de cuestiones que, a modo meramente ejemplar y conforme al inciso tercero del artículo 16 del Código Civil, deben entenderse sujetas a la LLS, sin limitar el alcance de esta regla a los demás aspectos del fondo del contrato.

En todo caso, esto no quiere decir que el artículo 113 sea superfluo. Su verdadero mérito está, ni más ni menos, que en admitir de manera expresa la autonomía de la voluntad conflictual, señalando que lo dispuesto en dicha norma rige solo "a menos que los contratantes hubieren acordado otra cosa”.

\subsection{Cuestiones sujetas a la LLS}

Como decíamos más arriba, el inciso tercero del artículo 16 establece que el contrato está sujeto a la LLS en todo cuanto concierne a su fondo. Pero ¿̨qué significa exactamente esto?

A nuestro juicio, un buen punto de partida lo constituyen las propias palabras de Bello. Para él, según vimos, "Todo contrato, por lo que toca a su valor, su inteligencia, las obligaciones que impone y el modo de llevarlas a efecto, debe arreglarse a las leyes del país en que se ajusta [celebra]; pero si ha de ejecutarse en otro país, se le aplican las leyes de este último" ${ }^{112}$. Este además es el mismo alcance que, como vimos, Story y Kent le atribuyen a la LLS.

En términos prácticos ${ }^{113}$, entonces, la validez y efectividad del acuerdo de voluntades (error, dolo, violencia, reserva metal, simulación, etc.) se regularán por la LLS ${ }^{114}$. La idonei-

\footnotetext{
109 Entre otros: Nussbaum (1942) pp. 893 y ss. Así, señala el autor, por ejemplo, que "under the Doctrine of the Restatement there is no to draw the line between the law of the place of contracting and the law of the place of performance", y MORRIS (1953) pp. 505 y ss.

110 Nussbaum (1942) p. 913.

111 Nussbaum (1942) p. 917.

112 Bello (1844) p. 73.

113 Aquí nos guiamos por Virgos Soriano (1995) pp. 108 y ss., quien trata esta materia a propósito del alcance de la lex contractus en el Convenio de Roma de 1980, hoy Reglamento Roma I.

114 En este sentido también: Rabel (1960) pp. 525 y ss.
} 
dad del objeto, la licitud de la causa, los elementos accidentales (condición, plazo, modo), la interpretación y los efectos del contrato (su fuerza obligatoria), correrán la misma suerte. A dicha ley corresponderá igualmente fijar los límites de la libertad contractual, de modo que las estipulaciones de las partes deberán conformarse a las prescripciones de dicho derecho y, en defecto de estas, el contrato producirá los mismos derechos y obligaciones que por su naturaleza le corresponden de acuerdo con la LLS.

Será esta ley, asimismo, la que regulará el cumplimiento e incumplimiento del contrato, sus causas y efectos, el alcance de la responsabilidad contractual, así como los remedios frente al incumplimiento. Ella determinará también las consecuencias de la nulidad del contrato.

Lo mismo ocurrirá, en general, con las causas de extinción o modificación de las obligaciones que no tengan naturaleza contractual. Y las que sí las tengan seguirán la misma suerte, a lo menos en cuanto a sus efectos sobre el contrato base. En lo demás, quedarán regidas por su propia lex contractus.

En cuanto a las acciones de garantía del derecho del acreedor que tiendan a afectar contratos posteriores con terceros, como la acción pauliana, se someten, en principio, a la ley que rige el negocio jurídico atacado.

Como vimos también, el cumplimiento de la obligación como acto de realización o ejecución de la prestación debida se rige igualmente por la ley rectora del contrato.

Hay que tener en cuenta, con todo, que una cierta interferencia del Derecho procesal del foro será inevitable, a lo menos, en lo que respecta a los procedimientos de ejecución forzosa. Estos, naturalmente, se regirán por la ley procesal del lugar donde deban realizarse, la cual condicionará, por ejemplo, la posibilidad de obligar a un cumplimiento forzoso en especie o solo por equivalencia, apremios disponibles, días y horas hábiles para el requerimiento, etc.

Otro tanto ocurre con los efectos reales del contrato sobre las cosas, los cuales se rigen por la lex rei sitae, de conformidad con el artículo 16 inciso primero.

En fin, no está dentro del alcance de este trabajo enumerar todas y cada una de las circunstancias que hacen excepción al principio de la unidad de régimen del contrato internacional.

\section{CONCLUSIONES}

Recapitulando, entonces, de acuerdo con el inciso segundo del artículo 16, el contrato se regula en todos sus aspectos por la ley del lugar en el cual se celebra. Esta regla, sin embargo, se ve alterada cuando el contrato ha de cumplirse en un lugar distinto de aquel donde se celebró, pues, siendo así, el inciso tercero dispone que el contrato quedará regido por la ley del lugar de su cumplimiento, salvo únicamente lo relativo a la forma que pudiera ser necesario observar conforme a la lex locus. En todo caso, incluso la forma del contrato puede ajustarse alternativamente a la LLS.

Ahora bien, más allá del énfasis que, según creemos, por razones históricas el artículo 16 pone en el lugar de celebración del contrato como punto de conexión, lo cierto es que 
una reflexión un poco más acabada nos debe llevar a concluir que la verdadera regla general es la LLS y no la LLC.

En efecto, el lugar de celebración solo opera cuando coincide con el lugar de cumplimiento. De lo contrario, el lugar de celebración -como punto de conexión- no juega ningún rol, a lo menos, en lo que respecta al fondo del contrato. El lugar de cumplimiento, en cambio, siempre deviene en la aplicación de la ley de dicho lugar: ya sea indirectamente, porque coincide con el lugar de celebración (inciso segundo del artículo 16), o bien de manera independiente y directa, en caso contrario (inciso tercero del artículo 16). Así, en una y otra hipótesis se aplica la LLS.

Por eso es que, a nuestro juicio, bien puede decirse, en términos prácticos y salvo las excepciones que ya hemos visto, que los contratos internacionales se rigen en Chile por la LLS, sin que ello importe desconocer lo dispuesto en el inciso segundo del artículo 16. Aquella es la verdadera lex contractus en materia de contratos internacionales en nuestro país.

\section{BIBLIOGRAFÍA}

Albónico, Fernando (1972): "Régimen Internacional de los Contratos por Correspondencia”, Revista de Derecho y Jurisprudencia, Tomo LIX: pp. 29-32.

Albónico, Fernando (1943): El Derecho Internacional Privado, Memoria de Prueba.

Albónico, Fernando (1950): Manual d Derecho Internacional Privado (Santiago, Editorial Jurídica)

Alcorta, Amancio (1927): Curso de derecho internacional privado. Tomo II (Buenos Aires, Facultad de Derecho y Ciencias Sociales).

Alessandri, Arturo, Somarriva Manuel y Vodanovic, Antonio (1998): Tratado de Derecho Civil. Partes Preliminar y General. (Santiago, Editorial Jurídica) 651 pp.

Aljure, Antonio (2007): "La ley aplicable a los contratos internacionales o con elementos extranjeros" en: Mantilla, F. y Ternera, F (Dirs.), Los contratos en el derecho privado Directores Académicos (Bogotá, Centro editorial de la Universidad del Rosario, Facultad de Jurisprudencia).

Beale, Joseph (1909) "What Law Governs the Validity of a Contract. I", Harvard Law Review, Vol. 23, No 1: pp. 1-11.

Bello, Andrés (1844): Principios del Derecho de Gentes (Madrid, Librería de la Señora Viuda de Calleja e Hijos) 408 pp.

Boggiano, Antonio (1995): Contratos Internacionales, Segunda edición (Buenos Aires, Ediciones DePalma) $177 \mathrm{pp}$.

Boggiano, Antonio (2000): Curso de Derecho Internacional Privado, Segunda edición ampliada y actualizada (Buenos Aires, Abeledo-Perrot) $1011 \mathrm{pp}$.

Boullenois, Louis (1766): Traité de la personnalité et de la réalité des loix. Tomo II (París, Guillaume Desprez) 596 pp.

Calvo Caravaca, Alfonso y Carrascosa, Javier (2012): “Contratos Internacionales I” en: Calvo Caravaca, A. y Carrascosa J., Derecho Internacional Privado, Volumen II, Parte Especial (Madrid, Editorial Comares) pp. 547-734. 
Carrascosa, Javier (1992): El Contrato Internacional: Fraccionamiento "Versus" Unidad (Madrid, Civitas Ediciones) 360 pp.

Carrascosa, Javier (2000): "Elección múltiple y elección parcial de la Ley aplicable al contrato internacional", Anales de derecho, ISSN 1989-5992, No 18: pp. 7-40.

Carrascosa, Javier (2003): "Contratos internacionales, prestación característica y la teoría de la Stream Of-Commerce”, en: A.L. Calvo Caravaca /P. Blanco-Morales, Globalización y Derecho (Madrid, Ed. Colex) pp. 87-119.

Carrascosa, Javier (2005): "La lucha por la prestación característica (I): Los contratos internacionales de distribución” en: Calvo Caravaca, A. y Areal Ludeña, (Directores), Cuestiones actuales del Derecho mercantil internacional (Madrid, Editorial Colex) pp. 397-420.

Claro Solar, Luis (1978): Explicaciones de Derecho Civil y Comparado. Tomo I (Santiago, Editorial Jurídica) 418 pp.

Domínguez, Raúl (1966): "Obligaciones, Contratos y Hechos Jurídicos”, en: Hamilton, Eduardo (edit.), Solución de Conflictos de Leyes y Jurisdicción (Santiago, Editorial Jurídica) $407 \mathrm{pp}$.

Domínguez Águila, Ramón (2013): Teoría General del Negocio Jurídico" (Santiago, Editorial Jurídica) 253 pp.

Ducci, Carlos (2000): Derecho Civil. Parte General. 4a Ed. (Santiago, Editorial Jurídica) 448 pp.

DunKer, Federico (1967): Derecho Internacional Privado. Parte General (Santiago, Editorial Jurídica de Chile) 473 pp.

Elliot, Jonathan (1834): The American Diplomatic Code. Vol. II (Washington, Jonathan Elliot) $703 \mathrm{pp}$.

Fabres, Clemente (1908): Obras Completas. Tomo Primero. Derecho Internacional Privado (Santiago, Imprenta Cervantes) 373 pp.

Feldstein, Sara (2000): Derecho internacional Privado. Parte Especial (Buenos Aires, editorial Universidad) $444 \mathrm{pp}$.

Fernández, José y Sánchez, Sixto (1999): Derecho Internacional Privado, Primera Edición (Madrid, Civitas Ediciones) 659 pp.

Fiore, Pascual (1878): Derecho Internacional Privado, Tomo Segundo (Madrid. F. Góngora y Compañía, Editores) 360 pp.

Foelix, Jean Jacques Gaspard (1960): Tratado de derecho internacional privado, ó Del conflicto de las leyes de diferentes naciones en materia de derecho privado. Tomo I, Tercera Edición (Madrid, Imprenta Revista de Legislación) 426 pp.

Goldschmidt, Werner (1990): Derecho Internacional Privado: Derecho de la Tolerancia (Buenos Aires, Ediciones DePalma) 849 pp.

GuZmán, Diego (1989): Tratado de Derecho Internacional Privado (Santiago, Editorial Jurídica) $656 \mathrm{pp}$.

Hartley, Trevor (2009): International Commercial Litigation: Text, Cases and Materials on Private International Law. (Cambridge University Press) 962 pp.

Kent, James (1832): Commentaries on American Law. Vol. II. Segunda Ed. (Nueva York, O. Halsted) $528 \mathrm{pp}$. 
Kaller de Orchansky, Berta (1990): Derecho Internacional Privado (Buenos Aires, Editorial DePalma).

Lando, Ole (1980): The Conflict of Laws of Contracts. General Principles, tomo 184 (La Haya, Recuel des Course de la Academie de Droit Internacional de la Haye).

McComic, R. Barry (1964): "Comments. Conflict of Laws in Louisiana: Contracts", Tulane Law Review, Vol. 38: pp. 726-754.

Maluenda, Rodrigo (1998): Contratos internacionales en el derecho chileno (Santiago de Chile, ConoSur) 389 pp.

MereminsKaya, Elina (2004): “Contratos internacionales e 'internacionalización’ de contratos nacionales", Anales de la Facultad de Derecho, Quinta época, No 1, Universidad de Chile, Santiago: pp. 111-128.

Morris, J.H.C (1953): "The eclipse of the lex loci solutionis- a fallacy exploded", The Vanderbilt Law Review, Volúmen 6, 1952-1953: pp. 505-533.

Nussbaum, Arthur (1942): "Conflict Theoris of Contracts: Cases versus Restatement", The Yale Law Journal, Volúmen 51, № 6: pp. 893-923.

Quintin, Alfonsín (1950): Régimen Internacional de los Contratos. (Montevideo, Biblioteca de Publicaciones Oficiales de la Facultad de Derecho y Ciencias Sociales de la Universidad de Montevideo) 190 pp.

Rabel, Ernst (1958): The conflict of laws: a comparative study. Vol. II. Foreign Corporations, Torts and Contracts in general, second edition (Ann Arbor, University of Michigan) 803 pp.

Ramírez, Mario (2007): Análisis crítico del Derecho internacional privado chileno (Santiago, LexisNexis) pp. 151.

Sandoval, Ricardo (2001): Derecho Comercial, 3a Ed., Tomo III, Vol. 1 (Santiago, Editorial Jurídica) $352 \mathrm{pp}$.

SAVIGNY (1849): System des heutigen römischen Rechts. Vol. 8. (Berlin, Bei Zeit und Comp.) 540 pp.

Siebel, Rolf (1934): "El derecho Internacional de las obligaciones", Revista de Derecho de la Universidad de Concepción, Año II, No 8 y 9: pp. 29-50.

STORY, Joseph (1834): Commentaries on the Conflict of Laws (Boston, Hilliard, Gray and Company) 557 pp.

WheAton, Henry (1855): Elements of International Law. 6a Ed. (Boston, Little, Brown and Company) 728 pp.

Wheeler CooK, Walter (1936): “Contracts' and the Conflict of Laws”, Illinois Law Review, Volumen XXXI, No 2: pp. 143-178.

Villarroel, Carlos y Villarroel, Gabriel (1990): “Determinación de la ley aplicable a los derechos y obligaciones emanados de los contratos internacionales", Revista Chilena de Derecho, 17 (2): pp. 351-365.

Virgos Soriano, Miguel (1989): Lugar de celebración y de ejecución en la contratación internacional (Madrid, Editorial Tecnos) 165 pp.

Virgos Soriano, Miguel (1995): “Obligaciones contractuales”, en GonZÁlez Campos, Julio (edit.), Derecho internacional privado. Parte especial, sexta edición revisada (Madrid, Eurolex) pp. 143-207. 
VOn IHERING, Rudolf (1998): El espiritu del derecho romano en las diversas facetas de su desarrollo, Tomo Primero (Granada, Editorial Comares).

\section{NORMAS CITADAS}

Código Civil.

Código de Comercio.

Ley $\mathrm{N}^{\circ}$ 19.971, sobre Arbitraje Comercial Internacional. Diario Oficial, 29 de septiembre de 2004.

Convención de Naciones Unidas sobre la Compraventa Internacional de Mercaderías de 1980, promulgada el 31 de mayo de 1990, en virtud del Decreto Supremo No 544 del Ministerio de Relaciones Exteriores. Diario Oficial, 3 de octubre de 1990.

Reglamento Consular, promulgada el 23 de marzo de 1977, en virtud del Decreto Supremo No 172 del Ministerio de Relaciones Exteriores. Diario Oficial, 29 de julio de 1977. Última versión del 28 de noviembre de 2009.

Convención de Viena de 1969 sobre el Derecho de los Tratados, promulgada mediante Decreto No 381 del Ministerio de Relacione Exteriores, publicado el 27 de enero de 1980.

Reglamento (CE) no 593/2008 del Parlamento Europeo y del Consejo, de 17 de junio de 2008, sobre la ley aplicable a las obligaciones contractuales (Roma I).

First Restatement of Conflict of Laws (1942).

Convención de La Haya de 1986 sobre ley aplicable a la compraventa internacional de mercaderías.

Convención de Nueva York de 1974 sobre prescripción en Materia de Compraventa Internacional de Mercaderías.

Convención Interamericana de 1994 sobre Derecho Aplicable a los Contratos Internacionales.

\section{JURISPRUDENCIA CITADA}

Charles Sencom y Cia. con A.R. Fallabela y Cía. (1927): Corte Suprema, 21 de diciembre de 1927 (casación en el fondo), Revista de Derecho y Jurisprudencia, T. 25, Sec. 1a, pp. 544 y ss.

Banco de Tacna con Espada y Donoso Hmnos. (1930): Corte Suprema, 9 de diciembre de 1930 (casación en el fondo), Revista de Derecho y Jurisprudencia, T. 28, Segunda Parte, Sec. $1^{\text {a }}$, p. 409.

Ferrer con Banco Español de Chile e Liquidación (1931): Corte de Apelaciones de Saniago, 13 de enero de 1931 (apelación), Revista de Derecho y Jurisprudencia, Tomo 30, sec. 2a, pp. 33 y ss.

Wulle-Herb, Margherite con Fisco (1954): Corte Suprema, 10 de mayo de 1954 (casación en el fondo), Revista de Derecho y Jurisprudencia, Tomo LI, sec. $1^{\circ}$, p. 340 y ss.

Galletti, Margarita con Lagos, Elvira (1954): Corte Suprema, 30 de agosto de 1954 (casación en el fondo), Revista de Derecho y Jurisprudencia, Tomo LI, sec. $1^{\circ}$ p. 110 y ss.

State Street Bank and Trust Company (2007): Corte Suprema, 14 de mayo de 2007 (exequatur), rol 2349-2005. 
Marlex Ltda. con European Industrial Engineering (2008): Corte Suprema, 28 de julio de 2008 (incidente de nulidad de todo lo obrado por incompetencia) rol 2026-2007.

"Van Riemsdyk v. Kane", 28 Fed. Cas 1062 (No 16.871) (C.C.R.I. 1812).

Corte de Apelaciones de Concepción, 3 de octubre de 1934 (apelación), Gaceta de los Tribunales, $1934,2^{\circ}$ sem., $\mathrm{N}^{\circ} 113$, p. 453 y ss.

Corte de Apelaciones de Concepción (1882): 14 de enero de 1882 (apelación), Gaceta de los Tribunales, $1882, \mathrm{~N}^{\circ} 129$, p. 81 y ss. 